\title{
STRESS-STRAIN RELATIONSHIP OF COLD-FORMED LEAN DUPLEX STAINLESS STEEL AT ELEVATED TEMPERATURES
}

\author{
Yuner Huang and Ben Young* \\ Department of Civil Engineering, The University of Hong Kong, Pokfulam Road, \\ Hong Kong, China
}

\begin{abstract}
A test program to examine the material properties of a relatively new cold-formed lean duplex stainless steel at elevated temperatures is presented. A total of 80 tensile coupon tests were carried out by both steady state test method and transient state test method for temperatures ranged from 24 to $900{ }^{\circ} \mathrm{C}$. The coupons were extracted from square and rectangular hollow sections. Material properties including thermal elongation, Young's modulus, yield strength, ultimate strength and ultimate strain were obtained. The test results and available data were compared with the design values in the European Code as well as a unified equation by Chen and Young [1] for stainless steel. The lean duplex stainless steel is not covered by these design rules. Reliability analysis was carried out to assess the applicability of these existing design rules. It is shown that the material properties of lean duplex stainless steel at elevated temperatures cannot be well predicted by the existing design rules. Modification to the existing design rules for lean duplex stainless steel at elevated temperatures is proposed. The stress-strain curves of the test specimens under different temperatures were plotted and compared with stress-strain curves predicted by the unified equation using modified coefficients. It is shown that the stress-strain curves and other material properties predicted by the modified design rules agree well with the test results.
\end{abstract}

Keywords: Elevated temperatures, fire resistance, lean duplex, material properties, stainless steel, steady state tests, transient state tests

\footnotetext{
${ }^{*}$ Corresponding author. Tel.: +852-2859-2674; fax: +852-2559-5337.

E-mail address: young@hku.hk (B. Young).
} 


\section{Introduction}

Fire is destructive in metal structures including stainless steel structures, due to its significantly reduced strength and stiffness at elevated temperatures. Accurate design rules are required to predict the material properties at elevated temperatures, which is important in structural design. Cold-formed lean duplex stainless steel (EN 1.4162), a recently developed high strength stainless steel with a relatively low price, has a great potential in construction industry. However, little research has been carried out on the material properties of lean duplex stainless steel at elevated temperatures, and this material is not covered in the existing design specifications for stainless steel structures. Therefore, it is necessary to investigate the material properties of cold-formed lean duplex stainless steel.

Chen and Young [1] investigated the material properties of duplex stainless steel grade EN 1.4462 (S31803) and austenitic stainless steel grade EN 1.4301 (AISI 304) at elevated temperatures. Unified equations to predict the material properties and stress-strain curves at different temperatures were proposed for the duplex stainless steel grade EN 1.4462 and austenitic stainless steel grade EN 1.4301. It is shown that the proposed design rules compared well with the test results. Gardner et al. [2] summarized test results on material properties of various stainless steel alloys at elevated temperatures, including the lean duplex stainless steel. Reduction factors of strength and stiffness for different types of stainless steel were proposed according to the available data.

Kouhi et al. [3] investigated the suitability of austenitic stainless steel grades EN 1.4571 and EN 1.4301 being used in buildings as load-bearing structures without fire protection. Tensile coupon tests at elevated temperatures were carried out, and the test results were compared with the existing design rules. It is found that the austenitic stainless steel is generally suitable to be used in constructions without fire protection. To and Young [4] investigated the performance of stainless steel tubular columns at elevated temperatures by carrying out finite element analysis. Two different design rules were proposed to determine the failure loads of cold-formed stainless steel tubular columns at elevated temperatures. Both methods were shown to be reliable and conservative based on reliability analysis. Feng and Young [5] performed numerical investigation on duplex EN 1.4462, high strength austenitic, and austenitic EN 1.4301 stainless steel in tubular joints at elevated temperatures. The existing design rules were assessed by comparing with the numerical results, and a new design equation was proposed by introducing a temperature factor. 
In this study, a test program to examine the material properties of cold-formed lean duplex stainless steel (EN 1.4162) at elevated temperatures using steady state test method and transient state test method is carried out. Tensile coupon tests were conducted for cold-formed lean duplex stainless steel specimens extracted from square and rectangular hollow sections. In the steady state tests, the test specimens were heated to a specified temperature and then imposed tensile stress to the specimens until failure; whereas in transient state tests, a constant tensile stress is applied to the specimens and then the temperature rises until the specimens fail. The nominal temperatures used in the coupon tests were ranged from $24-900{ }^{\circ} \mathrm{C}$, while the stress levels applied to the specimens in transient state tests were from $0-750$ MPa. The test results were compared with the design values given by EC3 [6] and Chen \& Young [1]. It should be noted that these design rules do not cover lean duplex stainless steel. Therefore, the duplex stainless steel (EN 1.4462) was used for comparison in this study. Reliability analysis was also performed to assess the design rules for lean duplex stainless steel. It is shown that the EC3 generally provides unconservative prediction, which may lead to an unsafe design of structures, while the unified equation provides generally conservative prediction to lean duplex stainless steel material properties at elevated temperatures. A set of coefficients for the unified equation in Chen and Young [1] were calibrated against the test data obtained from the lean duplex stainless steel. The design predictions were compared with the steady and transient state tests obtained from this study as well as compared with the available test data [2]. It is shown that the material properties predicted by the modified design rules conform well to the test results.

\section{Experimental Investigation}

\subsection{General}

Coupon tests were conducted at elevated temperatures to determine the material properties of the coupon specimens. The specimens were extracted from cold-formed lean duplex stainless steel rectangular hollow sections (RHS) and square hollow section (SHS) with nominal dimension $(D \times B \times t) 50 \times 30 \times 2.5,50 \times 50 \times 1.5$, and $150 \times 50 \times 2.5$, where $D, B, t$ are the depth, width, and thickness in millimetre of the cross-sections, respectively. The coupons were taken from the centre of the face at $90^{\circ}$ angle from the weld for all specimens, as shown in Fig. 1. The dimensions of coupon specimens conformed to the Australian Standard AS 2291 [7] and the American Standard ASTM E 21 [8] for the tensile testing of metals at elevated temperatures using a $6 \mathrm{~mm}$ wide coupon and a gauge length of $25 \mathrm{~mm}$, as shown in Fig. 2. 
The test set-up is shown in Fig. 3. An MTS testing machine was used to conduct the coupon tests. The MTS high temperature furnace with a maximum temperature of $1400{ }^{\circ} \mathrm{C}$ was used to specify the required temperatures during testing, with an accuracy of $1{ }^{\circ} \mathrm{C}$. There are three heating elements located at the upper, middle and lower part on each of the two sides of the furnace. Three internal thermal couples were located inside the furnace to measure the air temperature, and one external thermal couple was attached at the mid-length of the coupon specimen to measure the temperature of the specimen. The calibrated extensometer of $25 \mathrm{~mm}$ gauge length with the range limitation of $\pm 2.5 \mathrm{~mm}$ was mounted onto the specimens to measure the longitudinal strain during the tests. For specimens with large elongation under high temperatures, the strain may exceed the range limit of the extensometer. The extensometer was reset manually when it approached approximately $80 \%$ of the range limit during testing to avoid any damage to the apparatus.

The specimens were labeled such that the test method, dimension of cross-section from which coupon specimens were extracted and the nominal temperature could be identified. For example, in the label $550 \times 50 \times 1.5 \mathrm{~T} 800^{\# 2}$, the first letter indicates the test method, where "S" represents steady state test method and " $T$ " represents transient state test method. The coupon specimen was extracted from cross-section of nominal dimension $50 \times 50 \times 1.5$ and was tested under nominal temperature of $800{ }^{\circ} \mathrm{C}$. If the location of fracture is outside the gauge length of a specimen, meaning that the extensometer could not capture all of the strain near failure. Hence, the strain at ultimate strength and fracture could not be accurately measured and these values were not reported. These specimens are labelled using a superscript \# followed by a number to identify the specimens failed outside the gauge length of the coupon specimens.

\subsection{Steady state tests}

In the steady state tests, a specimen is heated up to a specified temperature and then loaded until it fails. The temperature is maintained when the tensile load is applied during testing. Coupons extracted from each hollow section are loaded under 10 different nominal temperatures from 24 to $900{ }^{\circ} \mathrm{C}$ with an interval of $100{ }^{\circ} \mathrm{C}$. Firstly, the upper end of the specimen was gripped, and the lower end of the specimen is free to expand during the heating process until it reaches a specified temperature. When the temperature on the specimen, which is measured by the external thermal couple, is stabilized at the specified temperature for 10 minutes, the lower end of the specimen is then gripped. Secondly, tensile load is applied to the specimen by displacement control with a constant loading rate of $0.5 \mathrm{~mm} / \mathrm{min}$ until it fails. The strain rate of the tests measured by the extensometer conformed to the Australian 
Standard AS 2291 [7] and American Standard ASTM E 21 [8]. A total of 44 coupon specimens were tested using steady state test method.

\subsection{Transient state tests}

In the transient state tests, a specimen is subjected to a specified tensile stress while the temperatures increase until the specimen fails. The nominal stress levels in this test program were $0,100,200,300,400,500,550,600,650,700$ and $750 \mathrm{MPa}$. Load control was used in the transient state tests so that a specified stress level can be maintained during the test. The air temperatures in the furnace increased in the rate of $15^{\circ} \mathrm{C} / \mathrm{min}$ until the specimen fails. The specimen temperatures were measured by the external thermal couple throughout the test. The test results of the transient state tests were converted to the stress-strain curves of the specimens at different specimen temperatures. The load level of $0 \mathrm{MPa}$ is to measure the thermal elongation of the specimens at elevated temperatures. The lower end of the specimen was free to expand, while the temperature increased from 24 to $1000^{\circ} \mathrm{C}$ in the rate of $15{ }^{\circ} \mathrm{C} / \mathrm{min}$. The thermal elongation is recorded by the extensometer mounted on the specimen during heating. A total of 36 coupon specimens were tested under transient state test method.

\section{Test results}

For steady state tests, the material properties measured at room temperature including Young's modulus $\left(E_{o}\right)$, yield strength $\left(f_{y}\right)$, which is also known as the $0.2 \%$ proof stress, $0.5 \%$ strength $\left(f_{0.5}\right), 1.0 \%$ strength $\left(f_{1.0}\right), 1.5 \%$ strength $\left(f_{1.5}\right), 2.0 \%$ strength $\left(f_{2.0}\right)$, ultimate tensile strength $\left(f_{u}\right)$, elongation at ultimate strength $\left(\varepsilon_{u}\right)$ and fracture $\left(\varepsilon_{f}\right)$ of a gauge length of $25 \mathrm{~mm}$, and the Ramberg-Osgood parameter $(n)$ using the Ramberg-Osgood expression $n=\ln (0.01 / 0.2) / \ln \left(f_{0.01} / f_{y}\right)$ are summarized in Table 1 . In the determination of the parameter $n$, the yield strength and $0.01 \%$ stress $\left(f_{0.01}\right)$ intersect points on the stress-strain curve were used, which are the proportional lines off-set by $0.2 \%$ and $0.01 \%$ strains, respectively. The $f_{0.5}, f_{1.0}, f_{1.5}$, and $f_{2.0}$ are the stresses corresponding to the intersect points of the stress-strain curve and the vertical line at a specified strain level, as shown in Fig 4. It is well known that the material properties reduce as the temperature increases. The reduction factors of Young's modulus $\left(E_{T} / E_{o}\right)$, yield strength $\left(f_{y, T} / f_{y}\right), 0.5 \%$ strength $\left(f_{0.5, T} / f_{0.5}\right), 1.0 \%$ strength $\left(f_{1.0, T} / f_{1.0}\right), 1.5 \%$ strength $\left(f_{1.5, T} / f_{1.5}\right), 2.0 \%$ strength $\left(f_{2.0, T} / f_{2.0}\right)$ and ultimate strength $\left(f_{u, T} / f_{u}\right)$, ultimate strain $\left(\varepsilon_{u, T} / \varepsilon_{u}\right)$ determined from the ratio of material properties at elevated temperatures to those at room temperature are summarized in Tables $2-4$ 
for sections $50 \times 30 \times 2.5,50 \times 50 \times 1.5$ and $150 \times 50 \times 2.5$, respectively. Some specimens failed outside the gauge length of the coupon specimens, and therefore the ultimate strains and the strains at fracture for these specimens are not reported. The actual specimen temperature was obtained by the average value of the specimen temperatures measured by the external thermal couple at the beginning, middle and end of each steady state test, as reported in Tables $2-4$. The actual specimen temperatures are close to the nominal temperatures with the maximum difference of $6.6 \%$ for the specimen $550 \times 30 \times 2.5 \mathrm{~T} 100^{\# 1}$. The comparison of the coupon specimens before and after tests at failure for different temperatures is shown in Fig 5.

For transient state tests, the test results were converted into stress-strain curves, as shown in Figs 6 - 8. The specimens were loaded under 11 different stress levels up to $750 \mathrm{MPa}$, which was maintained throughout the tests. The strains under a specified stress level were measured as the temperature increases until the failure of the specimen. Hence, the stress-strain curves at specified temperatures were plotted, as shown in Figs $6-8$. The material properties obtained from the stress-strain curves from transient state test results under room temperature are summarized in Table 5, using the definitions of symbol as shown in Fig. 4. The reduction factors $\left(E_{T} / E_{o}, f_{y, T} / f_{y}\right.$, and $\left.f_{0.5, T} / f_{0.5}\right)$ for the coupons extracted from the three sections are summarized in Table 6. It should be noted that the strain increased quickly near the failure load under load control. The extensometer was removed before the fracture of the coupon specimens in order to avoid the damage of the extensometer. Therefore, ultimate strain $\left(\varepsilon_{u}\right)$ and strain at fracture $\left(\varepsilon_{f}\right)$ cannot be recorded in transient state tests. In addition, the ultimate strengths $\left(f_{u}\right)$ may not occur at the 11 specified stress levels in the transient state tests as shown in Figs 6 - 8. Thus, the stress-strain curves in Figs 6 - 8 cannot be plotted up to the ultimate strength. The thermal elongations of coupon specimens extracted from each of the three sections were plotted against the specimen temperatures, as shown in Fig 9. Generally speaking, the thermal elongations of the coupon specimens increase linearly with the specimen temperatures. The reduction factors of Young's modulus $\left(E_{T} / E_{o}\right)$, yield strength $\left(f_{y, T} / f_{y}\right)$, ultimate strength $\left(f_{u, T} / f_{u}\right)$ and ultimate strain $\left(\varepsilon_{u, T} / \varepsilon_{u}\right)$ obtained from both steady and transient state test methods are plotted against the specimen temperatures in Figs 10-13, respectively.

\section{Comparison of test results with existing design rules}

\subsection{Design rules}

A total of 11 test data of the reduction factors of yield strength ( $0.2 \%$ proof stress) 
and ultimate strength for lean duplex stainless steel sheets under transient state tests were reported by Gardner et al. [2]. Test results of lean duplex stainless steel material properties at elevated temperatures obtained from this study and the available data [2] are compared with design values using European Code [6] and unified equations proposed by Chen and Young [1].

For the European Code, the reduction factors of Young's modulus, yield strength and ultimate strength at elevated temperatures for various stainless steel grades are provided in Table C.1 of the Eurocode 3: Design of steel structures - Part 1-2: General rules - Structural fire design [6]. However, the lean duplex stainless steel of Grade 1.4162 is not covered by the Code. Therefore, the reduction factors of duplex stainless steel (EN 1.4462) are used to compare with the test results to assess its suitability for lean duplex stainless steel (EN 1.4162). The reduction factors in European Code are provided for discrete temperatures only, thus linear interpolation was assumed to obtain the reduction factors corresponding to the actual temperatures on the test specimens.

Chen and Young [1] proposed unified Equations $(1-4)$ to predict the reduction factors of Young's modulus, yield strength, ultimate strength and ultimate strain for stainless steel at elevated temperatures, respectively, and the equations are follows:

$$
\begin{aligned}
& \frac{E_{T}}{E_{o}}=a-\frac{(T-b)^{n}}{c} \\
& \frac{f_{y, T}}{f_{y}}=a-\frac{(T-b)^{n}}{c} \\
& \frac{f_{u, T}}{f_{u}}=a-\frac{(T-b)^{n}}{c} \\
& \frac{\varepsilon_{u, T}}{\varepsilon_{u}}=a-\frac{(T-b)^{n}}{c}
\end{aligned}
$$

Two sets of coefficients $(a, b, c, n)$ were calibrated for stainless steel types EN 1.4462 (Duplex) and EN 1.4301 (AISI 304). The unified equations with coefficients for stainless steel type EN 1.4462 (Duplex) are used to compare with the test results in this study and the available data, in order to assess its suitability for lean duplex stainless steel. 


\subsection{Reliability analysis}

The reliability of the design rules for the prediction of the lean duplex stainless steel material properties at elevated temperatures was evaluated using reliability analysis, which is detailed in the Commentary of the ASCE [9]. However, target reliability index $\left(\beta_{0}\right)$ and the resistance factor $\left(\phi_{0}\right)$ for stainless steel material property are not suggested by the design specifications. Therefore, the target reliability index of 2.50 for stainless steel material property is adopted in this study. If the reliability index is greater than or equal to 2.50, then the design rules are considered to be reliable. The resistance factors of the design rules were determined using Eq. 6.2-2 of the ASCE Specification [9]. The load combinations of 1.35DL+1.5LL and 1.2DL+1.6LL, respectively, were used in calculating the resistance factors $\left(\phi_{0}\right)$ for EC3 [6] and the unified equations [1], where DL is the dead load and LL is the live load. The number of data used in the reliability analysis to obtain the reduction factors of Young's modulus, yield strength and ultimate strength are summarized in Table 7. The statistical parameters $M_{m}=1.10, F_{y m}=1.00, V_{y m}=0.10$ and $V_{F}=0.05$, which are the mean values and coefficients of variation for material properties and fabrication factors for yield strength and Young's modulus in the commentary of the ASCE Specification [9] were adopted for yield strength and Young's modulus at elevated temperatures. The statistical parameters $M_{m}=1.10, F_{u m}=1.00, V_{u m}=0.05$ and $V_{F}=$ 0.05 for ultimate strength in the commentary were also adopted for ultimate strength at elevated temperatures. The mean value $\left(P_{m}\right)$ and coefficient of variation of tested-to-predicted load ratio $\left(V_{p}\right)$ are shown in Table 8. The correction factor Eq. F1.1-3 in the North American Cold-formed Steel Specification AISI S100 [10] was used to account for the influence by the number of data. For the purpose of direct comparison, a load combination of 1.2DL + 1.6LL was used to calculate the resistance factors $\left(\phi_{1}\right)$, as shown in Table 8.

\subsection{Comparison with design rules}

The thermal elongation of the test specimens at elevated temperatures is compared with the thermal elongation predicted by EC3 [6] for austenitic stainless steel, as shown in Fig. 9. The EC3 [6] does not have the stainless steel grades of duplex nor lean duplex. Therefore, the thermal elongation of austenitic stainless steel obtained from EC3 [6] is plotted. It is shown that the EC3 prediction for austenitic stainless steel provide higher values of strain at any given temperatures compared with the test results of lean duplex stainless steel. It is observed that the strains of coupon specimens extracted from sections $50 \times 30 \times 2.5$ and $50 \times 50 \times 1.5$ are generally 
increased at the same rate as the temperature increases, while that of the coupon specimen extracted from section $150 \times 50 \times 2.5$ increased in a lower rate.

The reduction factors of Young's modulus of the test specimens at elevated temperatures are compared with those predicted by EC3 [6] and unified equation by Chen and Young [1] for duplex stainless steel of Grade EN 1.4462. The comparison of the reduction factors are shown in Table 8 and Fig. 10 , where $k_{E, T e s t}, k_{E, E C 3}$, and $k_{E \text {,Chen\&Young }}$ are the reduction factors of Young's modulus obtained from the test results, prediction values by EC3 and prediction values by the unified equation, respectively. The reduction factors of Young's modulus of the test specimens and design values are plotted against the specimen temperatures in Fig. 10. It is observed that the predictions by EC3 are unconservative for the test specimens, which may lead to an unsafe design. The mean value of $k_{E, T e s t} / k_{E, E C 3}$ equals to 0.86 , with the coefficient of variation (COV) of 0.168 . The resistance factors ( $\phi_{o}$ and $\phi_{1}$ ) of 0.65 are recommended for the reliabilities indices ( $\beta_{0}$ and $\beta_{1}$ ) equal to 2.50 and 2.60 , respectively. However, the unified equation provides quite conservative predictions for the Young's modulus of lean duplex stainless steel at elevated temperatures. The mean value of $k_{E \text {,Test }} / k_{E \text {,Chen\&Young }}$ equals to 1.42 , with a large value of COV equals to 0.303. The resistance factors $\left(\phi_{o}\right.$ and $\left.\phi_{1}\right)$ of 0.85 are recommended for the reliabilities indices $\left(\beta_{0}\right.$ and $\beta_{1}$ ) equal to 2.57 , which is greater than the target reliability index of 2.50. It is found that these two existing design rules cannot provide accurate predictions of Young's modulus for lean duplex stainless steel at elevated temperatures.

The reduction factors of yield strength of the test specimens and the available data at elevated temperatures are also compared with the design values by the two design rules, as shown in Table 8 and Fig. 11 , where $k_{y, T e s t}, k_{y, E C 3}$ and $k_{y, C h e n \& Y o u n g}$ are the reduction factors of yield strength obtained from test results, prediction values by EC3 and prediction values by the unified equation [1], respectively. Once again, the EC3 [6] is unconservative in predicting the yield strength reduction factors of lean duplex stainless steel at elevated temperatures. The mean value of $k_{y, T e s t} / k_{y, E C 3}$ is 0.89 , with COV of 0.182 . The resistance factors $\left(\phi_{o}\right.$ and $\left.\phi_{1}\right)$ of 0.65 are recommended to achieve the reliabilities indices $\left(\beta_{0}\right.$ and $\beta_{1}$ ) of 2.50 and 2.65. On the other hand, the unified equation for yield strength provides a conservative prediction. The mean value of $k_{y, \text { Test }} / k_{y}$,Chen\&Young equals to 1.07 , with the COV of 0.178 . Reliability indices $\left(\beta_{0}\right.$ and $\beta_{1}$ ) of 2.60 could be achieved by adopting the resistance factors ( $\phi_{o}$ and $\left.\phi_{1}\right)$ of 0.80 .

Comparison between the reduction factors of ultimate strength of the test specimens and the available data with the design values are shown in Table 8 and Fig. 
12 , where $k_{u, T e s t}, k_{u, E C 3}$, and $k_{u, C h e n \& Y o u n g}$ are the reduction factors of ultimate strength obtained from test results, prediction values by EC3 [6] and prediction values by the unified equation [1], respectively. It is shown that the predictions by both design rules are generally unconservative, with the mean values of $k_{u, T e s t} / k_{u, E C 3}$ and

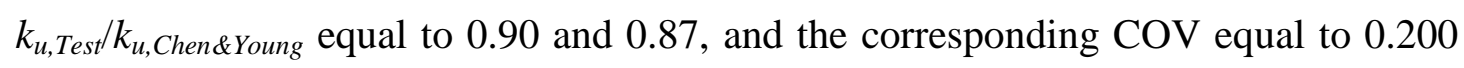
and 0.186, respectively. Resistance factors ( $\phi_{o}$ and $\left.\phi_{1}\right)$ of 0.65 and 0.70 are recommended for EC3 [6] to obtain the reliability indices $\left(\beta_{0}\right.$ and $\left.\beta_{1}\right)$ of 2.65 and 2.55 , respectively; while the resistance factors $\left(\phi_{o}\right.$ and $\left.\phi_{1}\right)$ of 0.70 are recommended for the reliability indices $\left(\beta_{0}\right.$ and $\beta_{1}$ ) of 2.50 for the unified equation.

Chen and Young [1] proposed an equation to predict the reduction factor of ultimate strain $\left(\varepsilon_{u, T} / \varepsilon_{u}\right)$ of duplex stainless steel EN 1.4462. Such prediction is compared with the test results of lean duplex, as shown Fig. 13. The design rule provides a generally conservative prediction to the reduction factor of ultimate strain for the lean duplex stainless steel at elevated temperatures. Therefore, the design equation for duplex stainless steel (EN 1.4462) is also recommended for lean duplex stainless steel (EN 1.4162) in predicting the ultimate strain at elevated temperatures.

\section{Design proposal for material properties at elevated temperatures}

According to the discussion earlier, modifications to design rules in predicting the Young's modulus, yield strength and ultimate strength for lean duplex stainless steel are necessary. The unified equations proposed by Chen and Young [1] are based on different set of coefficients ( $a, b, c$ and $n$ ) for different types of stainless steel at elevated temperatures, but lean duplex stainless steel is not included in the proposed equations. Therefore, the coefficients used in Eqs. $(1-3)$ proposed by Chen and Young [1] for Young's modulus, yield strength and ultimate strength are calibrated for lean duplex stainless steel test results.

The proposed coefficients to calculate the reduction factors of Young's modulus, yield strength and ultimate strength at elevated temperatures are summarized in Table 9. The material properties calculated by these proposed coefficients using Eqs. $(1-3)$ are compared with the test results, as shown in Table 8 and Figs. $10-12$. Reliability analysis was also carried out for the modified design rule in this study with the load combination of 1.2DL+1.6LL, as shown in Table 8. The predictions calculated from Eqs. $(1-3)$ using the proposed coefficients in this study as shown in Table 9 agree well with the test data of lean duplex stainless steel. The mean values of $k_{E, \text { Test }} / k_{E, \text { Modified }}, k_{y, \text { Test }} / k_{y, \text { Modified }}$ and $k_{u, \text { Test }} / k_{u, \text { Modified }}$ equal to $1.04,1.01$ and 1.00 , with 
the corresponding COV of 0.109, 0.126, and 0.124, respectively. The resistance factors $\left(\phi_{o}\right.$ and $\phi_{1}$ ) of $0.85,0.80$ and 0.85 are recommended for $k_{E, \text { Test }} / k_{E, \text { Modified, }}$ $k_{y, \text { Test }} / k_{y, \text { Modified }}$ and $k_{u, \text { Test }} / k_{u, \text { Modified }}$ to achieve the reliability indices of 2.60, 2.65 and 2.65, respectively. Therefore, comparing with the EC3 [6] and Chen and Young [1] design rules, the modified design rule provides more accurate, less scatter and more reliable predictions for the lean duplex stainless steel material properties at elevated temperatures, as shown in Table 8.

The stress-strain curve model in Chen and Young [1] is also compared with the stress-strain curves of the lean duplex stainless steel test specimens, as shown in Figs 14 - 19. In calculating the proposed stress-strain curves, the Young's modulus, yield strength and ultimate strength were obtained using the proposed coefficients for lean duplex stainless steel in this study as shown in Table 9, while the ultimate strain was obtained by the coefficients in Chen and Young [1] for duplex stainless steel. The full range of stress-strain curves up to ultimate strength for the test specimens under steady state tests are plotted and compared with the predicted stress-strain curves in Figs $14-19$. The proposed model covers the full range of stress-strain curves up to the ultimate strength for temperatures ranged from 24 to $900{ }^{\circ} \mathrm{C}$. It is shown that the predicted stress-strain curves using the proposed coefficients for lean duplex stainless steel generally agree well with the stress-strain curves obtained from the tests at elevated temperatures. Therefore, it is recommended that the stress-strain curve model in Chen and Young [1] together with the proposed coefficients in this study at elevated temperatures can be used for cold-formed lean duplex stainless steel. The stress-strain curve model for lean duplex stainless steel will facilitate future research on the structural behaviour at elevated temperatures, especially for numerical investigation.

\section{Conclusions}

An experimental investigation of material properties of lean duplex stainless steel at elevated temperatures has been presented. The test specimens are extracted from square and rectangular hollow sections of lean duplex stainless steel type EN 1.4162. Tensile coupon tests using steady state test method at different temperatures ranged from 24 to $900{ }^{\circ} \mathrm{C}$ were conducted. In addition, transient state tests at different stress levels ranged from 0 to $750 \mathrm{MPa}$ were also conducted. Material properties including the thermal elongation, Young's modulus, yield strength, ultimate strength and ultimate strain at elevated temperatures were obtained. The test results obtained in this study together with the available data were compared with design predictions by the 
EC3 [6] and Chen and Young [1]. It is shown that the thermal elongation and ultimate strain of lean duplex stainless steel can be generally predicted by EC3 [6] and the unified equation proposed by Chen and Young [1], respectively. It is also shown that the EC3 [6] provides generally unconservative predictions to the Young's modulus, yield strengths and ultimate strengths. The unified equations provide quite conservative predictions for Young's modulus, conservative predictions for yield strength, but unconservative predictions to ultimate strength. It is apparently shown that the current design rules are generally inappropriate for lean duplex stainless steel at elevated temperatures.

A new set of coefficients was calibrated against the lean duplex stainless steel tests for Young's modulus, yield strength and ultimate strength at elevated temperatures. It is shown that the predicted material properties obtained by the unified equations using the proposed coefficients in this study compare well with the test results. The modified design rules are generally more accurate and reliable than the current design rules. Furthermore, the stress-strain curve model in Chen and Young [1] together with the proposed coefficients at elevated temperatures for cold-formed lean duplex stainless steel is compared with the steady state test results. It is shown that the predicted stress-strain curves agree well with the test curves for the whole range up to the ultimate strength at elevated temperatures. Therefore, it is recommended that the design proposal of material properties at elevated temperatures can be used for cold-formed lean duplex stainless steel.

\section{Acknowledgements}

The authors are grateful to STALA Tube Finland for supplying the test specimens. The authors are also thankful to Mr. Kwai-Mo Tse for his assistance in the experimental program as part of his final year undergraduate research project at the University of Hong Kong. The research work described in this paper was supported by a grant from the Research Grants Council of the Hong Kong Special Administrative Region, China (Project No. HKU718612E). 


\section{Notation}

The following symbols are used in this paper:

$a$

$B$

$b$

COV

C

D

$E_{o}$

$E_{T}$

$F_{\text {um }}$

$F_{y m}$

$f_{y}$

$f_{y, T}$

$f_{u}$

$f_{u, T}$

$f_{0.01}$

$f_{0.5}$

$f_{0.5, T}$

$f_{1.0}$

$f_{1.0, T}$

$f_{1.5}$

$f_{1.5, T}$

$f_{2.0}$

$f_{2.0, T}$

$k_{E}$

$k_{E, \text { Chen\&Young }}$ coefficient used in modified equations;

width of cross-section;

coefficient used in modified equations;

coefficient of variation;

coefficient used in modified equations;

depth of cross-section;

initial Young's modulus;

initial Young's modulus at temperature $T^{\circ} \mathrm{C}$;

mean value of fabrication factor for ultimate strength;

mean value of fabrication factor for yield strength and Young's

modulus;

yield strength at room temperature;

yield strength at temperature $T^{\circ} \mathrm{C}$;

ultimate strength at room temperature;

ultimate strength at temperature $T^{\circ} \mathrm{C}$;

strength at $0.01 \%$ strain at room temperature;

strength at $0.5 \%$ strain at room temperature;

strength at $0.5 \%$ strain at temperature $T^{\circ} \mathrm{C}$;

strength at $1.0 \%$ strain at room temperature;

strength at $1.0 \%$ strain at temperature $T^{\circ} \mathrm{C}$;

strength at $1.5 \%$ strain at room temperature;

strength at $1.5 \%$ strain at temperature $T^{\circ} \mathrm{C}$;

strength at $2.0 \%$ strain at room temperature;

strength at $2.0 \%$ strain at temperature $T^{\circ} \mathrm{C}$;

reduction factor of Young's modulus at elevated temperatures;

reduction factor of Young's modulus at elevated temperatures predicted by Chen \& Young [1]; 


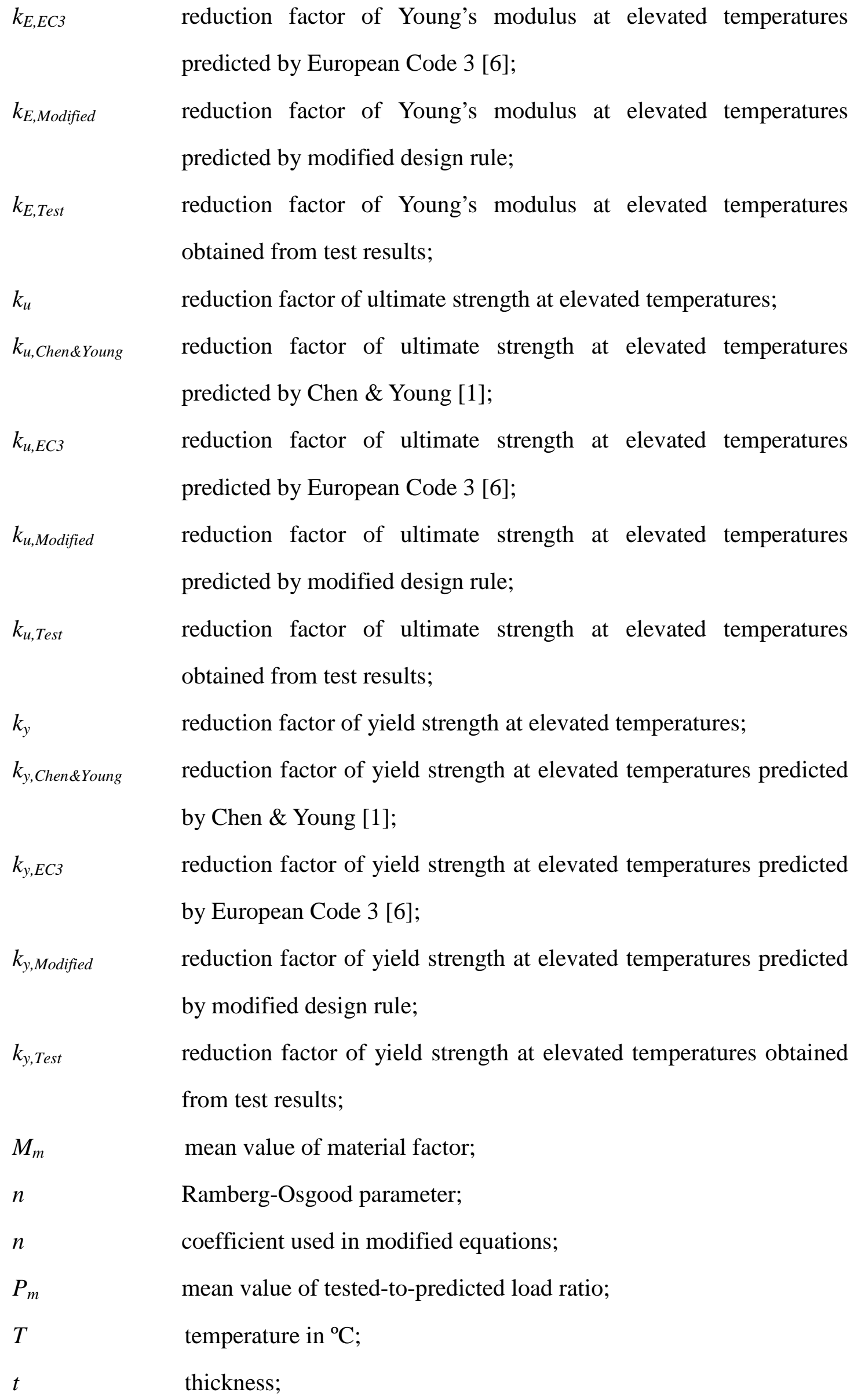




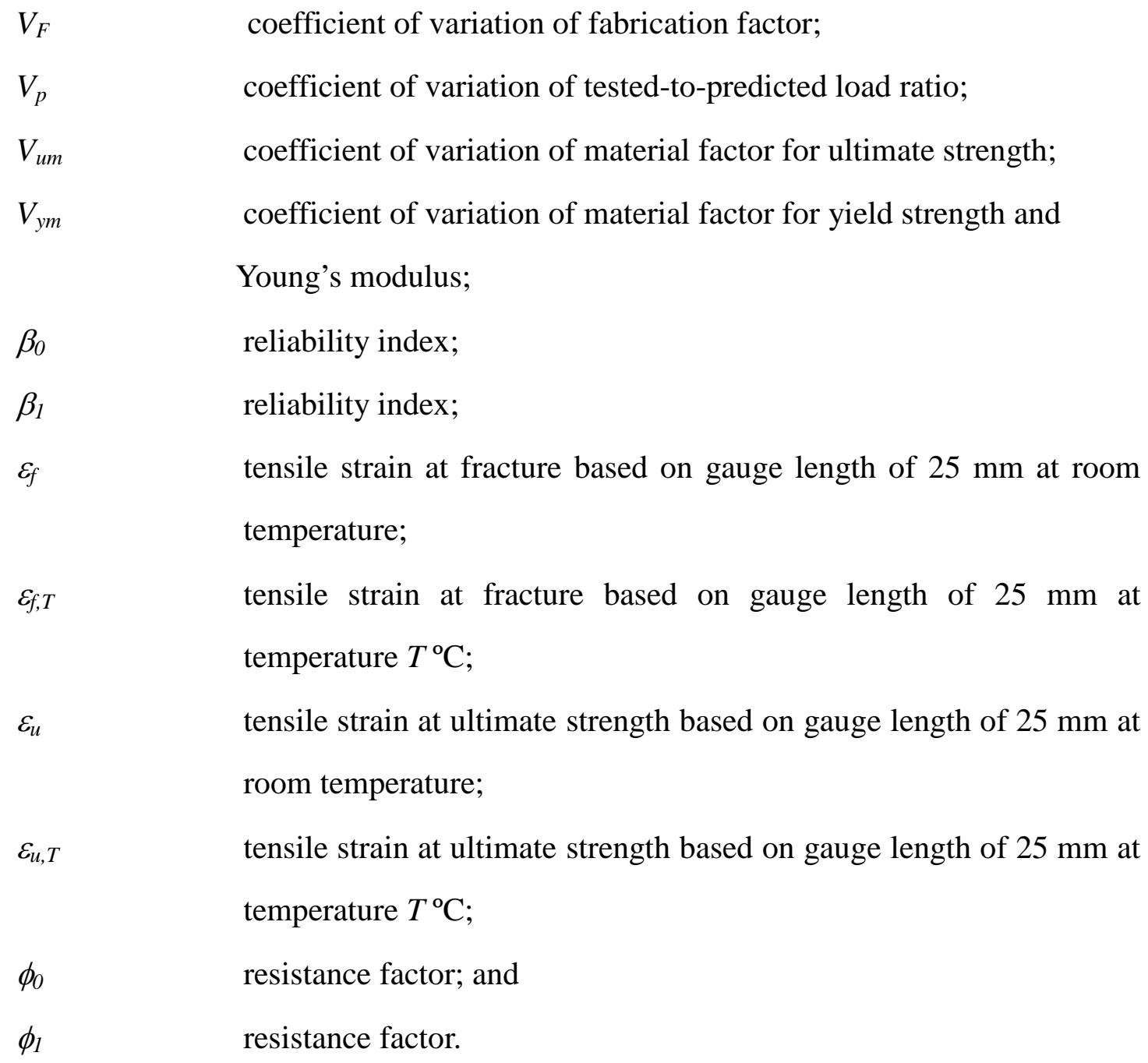




\section{References}

[1] Chen J, Young B. Stress-strain curves for stainless steel at elevated temperatures. Eng Struct 2006; 28(2): 229-39.

[2] Gardner L, Insausti A, Ng KT, Ashraf M. Elevated temperature material properties of stainless steel alloys. J Constr Steel Res 2010; 66(5): 634-47.

[3] Kouhi J, Talja A, Salmi P, Ala-Outinen T. Current R\&D work on the use of stainless steel in construction in Finland. J Constr Steel Res 2000; 54(1): 31-50.

[4] To EC, Young B. Performance of cold-formed stainless steel tubular columns at elevated temperatures. Eng Struct 2008; 30 (7): 2012-21.

[5] Feng R, Young B. Design of cold-formed stainless steel tubular joints at elevated temperatures. Eng Struct 2012; 35: 188-202.

[6] EC3. Design of steel structures - part 1-2: general rules - structural fire design. European Committee for Standardization, EN 1993-1-2. Brussels: CEN; 2005.

[7] AS 2291. Methods for the tensile testing of metals at elevated temperatures. Australian Standard. Standard Association of Australia, Australia; 1979.

[8] ASTM E 21. Standard test methods for elevated temperature tension tests of metallic materials. American Society for Testing and Materials, West Conshohocken, USA; 1992.

[9] ASCE. Specification for the design of cold-formed stainless steel structural members. SEI/ASCE 8-02. Reston, VA: American Society of Civil Engineers; 2002.

[10] AISI S100. North American Specification for the design of cold-formed steel structural members. North American Cold-formed Steel Specification. Washington D.C.: American Iron and Steel Institute, AISI S100-2007; 2007. 


\begin{tabular}{|c|c|c|c|c|c|c|c|c|c|c|c|}
\hline Specimen & $T\left({ }^{\circ} \mathrm{C}\right)$ & $\begin{array}{c}E_{o} \\
(\mathrm{GPa})\end{array}$ & $\begin{array}{c}f_{y} \\
(\mathrm{MPa})\end{array}$ & $\begin{array}{c}f_{0.5} \\
(\mathrm{MPa})\end{array}$ & $\begin{array}{c}f_{1.0} \\
(\mathrm{MPa})\end{array}$ & $\begin{array}{c}f_{1.5} \\
(\mathrm{MPa})\end{array}$ & $\begin{array}{c}f_{2.0} \\
(\mathrm{MPa})\end{array}$ & $\begin{array}{c}f_{u} \\
(\mathrm{MPa})\end{array}$ & $\begin{array}{c}\varepsilon_{u} \\
(\%)\end{array}$ & $\begin{array}{c}\varepsilon_{f} \\
(\%)\end{array}$ & $n$ \\
\hline $\mathrm{S} 50 \times 30 \times 2.5 \mathrm{~T} 24$ & 24.6 & 203 & 722.1 & 700.8 & 782.2 & 796.7 & 802.3 & 829.7 & 16.4 & 27.2 & 5.9 \\
\hline S50×50×1.5T24 & 24.2 & 199 & 682.4 & 666.5 & 730.6 & 748.8 & 753.7 & 828.1 & 21.5 & 30.6 & 6.4 \\
\hline
\end{tabular}

Table 1: Material properties obtained from steady state tests at room temperature 


\begin{tabular}{|c|c|c|c|c|c|c|c|c|c|}
\hline Specimen & $T\left({ }^{\circ} \mathrm{C}\right)$ & $\frac{E_{T}}{E_{o}}$ & $\frac{f_{y, T}}{f_{y}}$ & $\frac{f_{0.5, T}}{f_{0.5}}$ & $\frac{f_{1.0, T}}{f_{1.0}}$ & $\frac{f_{1.5, T}}{f_{1.5}}$ & $\frac{f_{2.0, T}}{f_{2.0}}$ & $\frac{f_{u, T}}{f_{u}}$ & $\frac{\varepsilon_{u, T}}{\varepsilon_{u}}$ \\
\hline S50×30×2.5T100 & 102.1 & 1.00 & 0.90 & 0.92 & 0.89 & 0.88 & 0.88 & 0.89 & 1.03 \\
\hline $\mathrm{S} 50 \times 30 \times 2.5 \mathrm{~T} 100^{\# 1}$ & 106.6 & 0.95 & 0.99 & 0.99 & 0.97 & 0.97 & 0.97 & 0.93 & --- \\
\hline S50×30×2.5T200 & 199.8 & 0.96 & 0.85 & 0.87 & 0.84 & 0.83 & 0.84 & 0.85 & 0.76 \\
\hline $\mathrm{S} 50 \times 30 \times 2.5 \mathrm{~T} 300$ & 308.6 & 0.77 & 0.79 & 0.78 & 0.81 & 0.82 & 0.87 & 0.83 & 0.70 \\
\hline $\mathrm{S} 50 \times 30 \times 2.5 \mathrm{~T} 400$ & 401.5 & 0.70 & 0.72 & 0.71 & 0.74 & 0.76 & 0.77 & 0.81 & 0.72 \\
\hline $\mathrm{S} 50 \times 30 \times 2.5 \mathrm{~T} 400^{\# 1}$ & 400.0 & 0.69 & 0.68 & 0.68 & 0.71 & 0.72 & 0.73 & 0.80 & --- \\
\hline S50×30×2.5T500 & 500.3 & 0.68 & 0.60 & 0.61 & 0.64 & 0.65 & 0.66 & 0.72 & 0.74 \\
\hline $\mathrm{S} 50 \times 30 \times 2.5 \mathrm{~T} 500^{\# 1}$ & 493.2 & 0.73 & 0.65 & 0.65 & 0.71 & 0.73 & 0.74 & 0.79 & --- \\
\hline S50×30×2.5T600 & 598.2 & 0.68 & 0.52 & 0.55 & 0.56 & 0.57 & 0.57 & 0.54 & 0.38 \\
\hline $\mathrm{S} 50 \times 30 \times 2.5 \mathrm{~T} 600^{\# 1}$ & 601.3 & 0.62 & 0.46 & 0.49 & 0.50 & 0.51 & 0.50 & 0.49 & --- \\
\hline $\mathrm{S} 50 \times 30 \times 2.5 \mathrm{~T} 700$ & 700.9 & 0.61 & 0.28 & 0.31 & 0.29 & 0.29 & 0.29 & 0.29 & 0.38 \\
\hline $\mathrm{S} 50 \times 30 \times 2.5 \mathrm{~T} 800$ & 803.2 & 0.31 & 0.19 & 0.20 & 0.19 & 0.19 & 0.19 & 0.18 & 0.18 \\
\hline $\mathrm{S} 50 \times 30 \times 2.5 \mathrm{~T} 900$ & 894.6 & 0.23 & 0.06 & 0.08 & 0.08 & 0.07 & 0.07 & 0.07 & 0.15 \\
\hline
\end{tabular}

\# Failed outside the gauge length of the coupon specimen

Table 2: Reduction factors of material properties of section $50 \times 30 \times 2.5$ at elevated temperatures obtained from steady state tests 


\begin{tabular}{|c|c|c|c|c|c|c|c|c|c|}
\hline Specimen & $T\left({ }^{\circ} \mathrm{C}\right)$ & $\frac{E_{T}}{E_{o}}$ & $\frac{f_{y, T}}{f_{y}}$ & $\frac{f_{0.5, T}}{f_{0.5}}$ & $\frac{f_{1.0, T}}{f_{1.0}}$ & $\frac{f_{1.5, T}}{f_{1.5}}$ & $\frac{f_{2.0, T}}{f_{2.0}}$ & $\frac{f_{u, T}}{f_{u}}$ & $\frac{\varepsilon_{u, T}}{\varepsilon_{u}}$ \\
\hline $\mathrm{S} 50 \times 50 \times 1.5 \mathrm{~T} 100$ & 98.7 & 0.98 & 0.94 & 0.96 & 0.92 & 0.92 & 0.92 & 0.97 & 0.90 \\
\hline $\mathrm{S} 50 \times 50 \times 1.5 \mathrm{~T} 200$ & 205.1 & 0.88 & 0.83 & 0.84 & 0.81 & 0.81 & 0.82 & 0.88 & 0.87 \\
\hline S50×50×1.5T300 & 303.2 & 0.94 & 0.75 & 0.78 & 0.80 & 0.81 & 0.83 & 0.84 & 0.77 \\
\hline $\mathrm{S} 50 \times 50 \times 1.5 \mathrm{~T} 400$ & 406.6 & 0.80 & 0.65 & 0.67 & 0.71 & 0.72 & 0.73 & 0.83 & 0.88 \\
\hline $\mathrm{S} 50 \times 50 \times 1.5 \mathrm{~T} 500$ & 508.2 & 0.70 & 0.55 & 0.57 & 0.61 & 0.62 & 0.62 & 0.72 & 0.81 \\
\hline $\mathrm{S} 50 \times 50 \times 1.5 \mathrm{~T} 600$ & 606.6 & 0.63 & 0.39 & 0.43 & 0.42 & 0.42 & 0.43 & 0.42 & 0.50 \\
\hline $\mathrm{S} 50 \times 50 \times 1.5 \mathrm{~T} 700$ & 695.9 & 0.61 & 0.31 & 0.32 & 0.32 & 0.31 & 0.32 & 0.30 & 0.48 \\
\hline $\mathrm{S} 50 \times 50 \times 1.5 \mathrm{~T} 800$ & 802.3 & 0.33 & 0.14 & 0.15 & 0.15 & 0.15 & 0.16 & 0.14 & 0.15 \\
\hline $\mathrm{S} 50 \times 50 \times 1.5 \mathrm{~T} 800^{\# 1}$ & 801.5 & 0.30 & 0.13 & 0.15 & 0.14 & 0.14 & 0.14 & 0.13 & --- \\
\hline $\mathrm{S} 50 \times 50 \times 1.5 \mathrm{~T} 800^{\# 2}$ & 811.0 & 0.29 & 0.12 & 0.15 & 0.15 & 0.14 & 0.15 & 0.14 & --- \\
\hline S50×50×1.5T900 & 904.8 & 0.28 & 0.04 & 0.05 & 0.05 & 0.05 & 0.05 & 0.04 & 0.12 \\
\hline
\end{tabular}

${ }^{\#}$ Failed outside the gauge length of the coupon specimen

Table 3: Reduction factors of material properties of section $50 \times 50 \times 1.5$ at elevated temperatures obtained from steady state tests 


\begin{tabular}{|c|c|c|c|c|c|c|c|c|c|}
\hline Specimen & $T\left({ }^{\circ} \mathrm{C}\right)$ & $\frac{E_{T}}{E_{o}}$ & $\frac{f_{y, T}}{f_{y}}$ & $\frac{f_{0.5, T}}{f_{0.5}}$ & $\frac{f_{1.0, T}}{f_{1.0}}$ & $\frac{f_{1.5, T}}{f_{1.5}}$ & $\frac{f_{2.0, T}}{f_{2.0}}$ & $\frac{f_{u, T}}{f_{u}}$ & $\frac{\varepsilon_{u, T}}{\varepsilon_{u}}$ \\
\hline S150×50×2.5T100 & 100.3 & 0.99 & 0.86 & 0.88 & 0.87 & 0.89 & 0.89 & 0.92 & 0.99 \\
\hline $\mathrm{S} 150 \times 50 \times 2.5 \mathrm{~T} 100^{\# 1}$ & 99.4 & 0.98 & 0.86 & 0.87 & 0.85 & 0.86 & 0.87 & 0.92 & --- \\
\hline S150×50×2.5T200 & 204.0 & 0.89 & 0.82 & 0.82 & 0.87 & 0.89 & 0.89 & 0.90 & 0.73 \\
\hline $\mathrm{S} 150 \times 50 \times 2.5 \mathrm{~T} 300$ & 299.4 & 0.94 & 0.72 & 0.74 & 0.78 & 0.80 & 0.81 & 0.84 & 0.72 \\
\hline $\mathrm{S} 150 \times 50 \times 2.5 \mathrm{~T} 400$ & 404.5 & 0.85 & 0.63 & 0.66 & 0.70 & 0.73 & 0.74 & 0.86 & 0.77 \\
\hline S150×50×2.5T500 & 502.6 & 0.74 & 0.51 & 0.54 & 0.57 & 0.60 & 0.60 & 0.71 & 0.84 \\
\hline $\mathrm{S} 150 \times 50 \times 2.5 \mathrm{~T} 500^{\# 1}$ & 500.3 & 0.71 & 0.56 & 0.59 & 0.63 & 0.66 & 0.68 & 0.76 & --- \\
\hline $\mathrm{S} 150 \times 50 \times 2.5 \mathrm{~T} 500^{\# 2}$ & 503.1 & 0.73 & 0.56 & 0.60 & 0.66 & 0.69 & 0.67 & 0.78 & --- \\
\hline S150×50×2.5T600 & 599.0 & 0.58 & 0.46 & 0.49 & 0.53 & 0.54 & 0.55 & 0.52 & 0.29 \\
\hline $\mathrm{S} 150 \times 50 \times 2.5 \mathrm{~T} 600^{\# 1}$ & 615.2 & 0.69 & 0.41 & 0.44 & 0.43 & 0.44 & 0.44 & 0.42 & --- \\
\hline $\mathrm{S} 150 \times 50 \times 2.5 \mathrm{~T} 600^{\# 2}$ & 600.0 & 0.56 & 0.42 & 0.44 & 0.44 & 0.46 & 0.46 & 0.45 & --- \\
\hline $\mathrm{S} 150 \times 50 \times 2.5 \mathrm{~T} 600^{\# 3}$ & 597.3 & 0.56 & 0.44 & 0.46 & 0.48 & 0.50 & 0.50 & 0.48 & --- \\
\hline $\mathrm{S} 150 \times 50 \times 2.5 \mathrm{~T} 700$ & 698.5 & 0.54 & 0.31 & 0.32 & 0.33 & 0.34 & 0.34 & 0.33 & 0.47 \\
\hline $\mathrm{S} 150 \times 50 \times 2.5 \mathrm{~T} 700^{\# 1}$ & 702.9 & 0.55 & 0.31 & 0.33 & 0.33 & 0.34 & 0.34 & 0.35 & --- \\
\hline S150×50×2.5T800 & 794.6 & 0.40 & 0.20 & 0.22 & 0.22 & 0.23 & 0.23 & 0.21 & 0.20 \\
\hline S150×50×2.5T900 & 902.1 & 0.24 & 0.11 & 0.11 & 0.11 & 0.11 & 0.11 & 0.10 & 0.16 \\
\hline
\end{tabular}

\# Failed outside the gauge length of the coupon specimen

Table 4: Reduction factors of material properties of section $150 \times 50 \times 2.5$ at elevated temperatures obtained from steady state tests 


\begin{tabular}{lccccc}
\hline Section & $T\left({ }^{\circ} \mathrm{C}\right)$ & $E_{o}(\mathrm{GPa})$ & $f_{y}(\mathrm{MPa})$ & $f_{0.5}(\mathrm{MPa})$ & $n$ \\
\hline $50 \times 30 \times 2.5$ & 26.0 & 189 & 620.0 & 610.2 & 4.6 \\
$50 \times 50 \times 1.5$ & 22.4 & 194 & 630.0 & 622.1 & 6.6 \\
$150 \times 50 \times 2.5$ & 26.3 & 205 & 664.3 & 658.8 & 11.4 \\
\hline
\end{tabular}

Table 5: Material properties obtained from stress-strain curves converted from transient state test results at room temperature 


\begin{tabular}{|c|c|c|c|c|c|c|c|c|c|}
\hline \multirow[b]{2}{*}{$T\left({ }^{\circ} \mathrm{C}\right)$} & \multicolumn{3}{|c|}{$50 \times 30 \times 2.5$} & \multicolumn{3}{|c|}{$50 \times 50 \times 1.5$} & \multicolumn{3}{|c|}{$150 \times 50 \times 2.5$} \\
\hline & $\frac{E_{T}}{E_{o}}$ & $\frac{f_{y, T}}{f_{y}}$ & $\frac{f_{0.5, T}}{f_{0.5}}$ & $\frac{E_{T}}{E_{o}}$ & $\frac{f_{y, T}}{f_{y}}$ & $\frac{f_{0.5, T}}{f_{0.5}}$ & $\frac{E_{T}}{E_{o}}$ & $\frac{f_{y, T}}{f_{y}}$ & $\frac{f_{0.5, T}}{f_{0.5}}$ \\
\hline 100 & 0.96 & 0.96 & 0.96 & 0.98 & 0.96 & 1.00 & 0.97 & 0.90 & 0.91 \\
\hline 150 & 0.85 & 0.97 & 0.94 & 0.95 & 0.91 & 0.95 & 0.97 & 0.83 & 0.87 \\
\hline 200 & 0.84 & 0.89 & 0.88 & 0.91 & 0.87 & 0.91 & 0.88 & 0.78 & 0.84 \\
\hline 250 & 0.84 & 0.87 & 0.87 & 0.83 & 0.87 & 0.90 & 0.82 & 0.77 & 0.80 \\
\hline 300 & 0.83 & 0.86 & 0.85 & 0.79 & 0.85 & 0.86 & 0.75 & 0.77 & 0.77 \\
\hline 350 & 0.74 & 0.81 & 0.78 & 0.77 & 0.76 & 0.79 & 0.73 & 0.70 & 0.71 \\
\hline 400 & 0.69 & 0.74 & 0.73 & 0.76 & 0.66 & 0.70 & 0.70 & 0.65 & 0.65 \\
\hline 450 & 0.63 & 0.70 & 0.69 & 0.73 & 0.65 & 0.68 & 0.71 & 0.56 & 0.58 \\
\hline 500 & 0.63 & 0.66 & 0.66 & 0.68 & 0.61 & 0.64 & 0.70 & 0.51 & 0.52 \\
\hline 550 & 0.60 & 0.65 & 0.64 & 0.66 & 0.51 & 0.55 & 0.64 & 0.47 & 0.48 \\
\hline 600 & 0.51 & 0.55 & 0.54 & 0.62 & 0.46 & 0.50 & 0.56 & 0.41 & 0.43 \\
\hline
\end{tabular}

Table 6: Reduction factors of material properties at elevated temperatures obtained from stress-strain curves converted from transient state test results 


\begin{tabular}{r|ccc}
\hline & \multicolumn{3}{|c}{ Number of data used to obtain the reduction factors } \\
\cline { 2 - 4 } & $k_{E}=\frac{E_{T}}{E_{o}}$ & $k_{y}=\frac{f_{y, T}}{f_{y}}$ & $k_{u}=\frac{f_{u, T}}{f_{u}}$ \\
\hline $50 \times 30 \times 2.5$ (Steady) & 14 & 14 & 14 \\
$50 \times 50 \times 1.5$ (Steady) & 12 & 12 & 12 \\
$150 \times 50 \times 2.5$ (Steady) & 18 & 18 & 18 \\
$50 \times 30 \times 2.5$ (Transient) & 12 & 12 & 0 \\
$50 \times 50 \times 1.5$ (Transient) & 12 & 12 & 0 \\
$150 \times 50 \times 2.5$ (Transient) & 12 & 12 & 11 \\
Reported in Gardner et. al [2] & 0 & 11 & 55 \\
\hline Total number of data & 80 & 91 & \\
\hline
\end{tabular}

Table 7: Number of data used to obtain reduction factors of material properties under elevated temperatures 


\begin{tabular}{|c|c|c|c|c|c|c|c|c|c|}
\hline & $\frac{k_{E, \text { Test }}}{k_{E, E C 3}}$ & $\frac{k_{E, \text { Test }}}{k_{E, \text { Chen\&Young }}}$ & $\frac{k_{E, \text { Test }}}{k_{E, \text { Modified }}}$ & $\frac{k_{y, \text { Test }}}{k_{y, E C 3}}$ & $\frac{k_{y, \text { Test }}}{k_{y, \text { Chen\&Young }}}$ & $\frac{k_{y, \text { Test }}}{k_{y, \text { Modified }}}$ & $\frac{k_{u, T e s t}}{k_{u, E C 3}}$ & $\frac{k_{u, \text { Test }}}{k_{u, \text { Chen\&Young }}}$ & $\frac{k_{u, \text { Test }}}{k_{u, \text { Modified }}}$ \\
\hline Mean $\left(P_{m}\right)$ & 0.86 & 1.42 & 1.04 & 0.89 & 1.07 & 1.01 & 0.90 & 0.87 & 1.00 \\
\hline $\operatorname{COV}\left(V_{p}\right)$ & 0.168 & 0.303 & 0.109 & 0.182 & 0.178 & 0.126 & 0.200 & 0.186 & 0.124 \\
\hline Reliability index $\left(\beta_{o}\right)$ & 2.50 & 2.57 & 2.60 & 2.50 & 2.60 & 2.65 & 2.65 & 2.50 & 2.65 \\
\hline Resistance factor $\left(\phi_{l}\right)$ & 0.65 & 0.85 & 0.85 & 0.65 & 0.80 & 0.80 & 0.70 & 0.70 & 0.85 \\
\hline Reliability index $\left(\beta_{l}\right)$ & 2.60 & 2.57 & 2.60 & 2.65 & 2.60 & 2.65 & 2.55 & 2.50 & 2.65 \\
\hline
\end{tabular}

Table 8: Reliability analysis for different design rules in predicting the reduction factors of material properties at elevated temperatures 


\begin{tabular}{cc|cccc}
\hline & $T\left({ }^{\circ} \mathrm{C}\right)$ & $a$ & $b$ & $c$ & $n$ \\
\hline \multirow{2}{*}{$E_{T}$} & $24<T \leq 700$ & 1 & 24 & 1384 & 1 \\
& $700<T \leq 900$ & 0.51 & 700 & 650 & 1 \\
\hline \multirow{4}{*}{$f_{y, T}$} & $24<T \leq 300$ & 1 & 24 & 284 & 0.75 \\
& $300<T \leq 600$ & 0.76 & 300 & 2930 & 1.2 \\
& $600<T \leq 900$ & 0.44 & 600 & 200 & 0.75 \\
\hline \multirow{4}{*}{$f_{u, T}$} & $24<T \leq 400$ & 0.85 & 400 & $3.25 \mathrm{E}+08$ & 3 \\
& $400<T \leq 600$ & 0.85 & 400 & 102560 & 2 \\
& $600<T \leq 900$ & 0.46 & 600 & 300 & 0.83 \\
\hline
\end{tabular}

Table 9: Proposed coefficients for lean duplex stainless steel (EN 1.4162) 


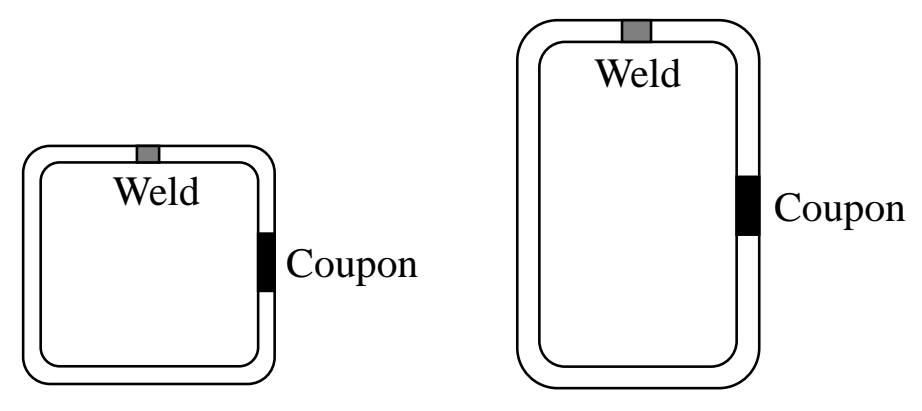

Fig 1: Location of coupon and weld in hollow sections 
536

$\sqrt[2]{243}$

Fig 2: Dimensions of coupon specimen 


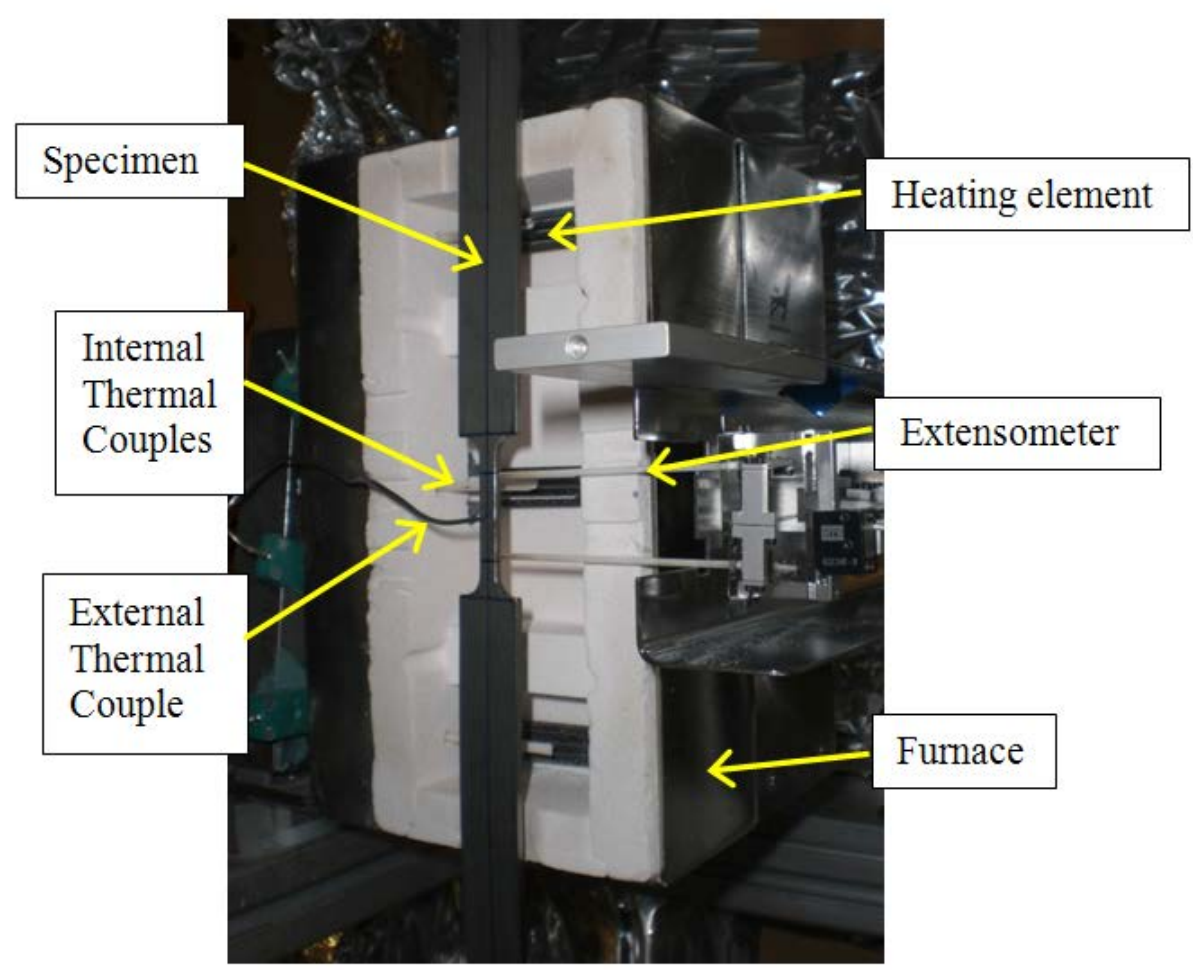

(a) One of the two sides of furnace and a coupon specimen

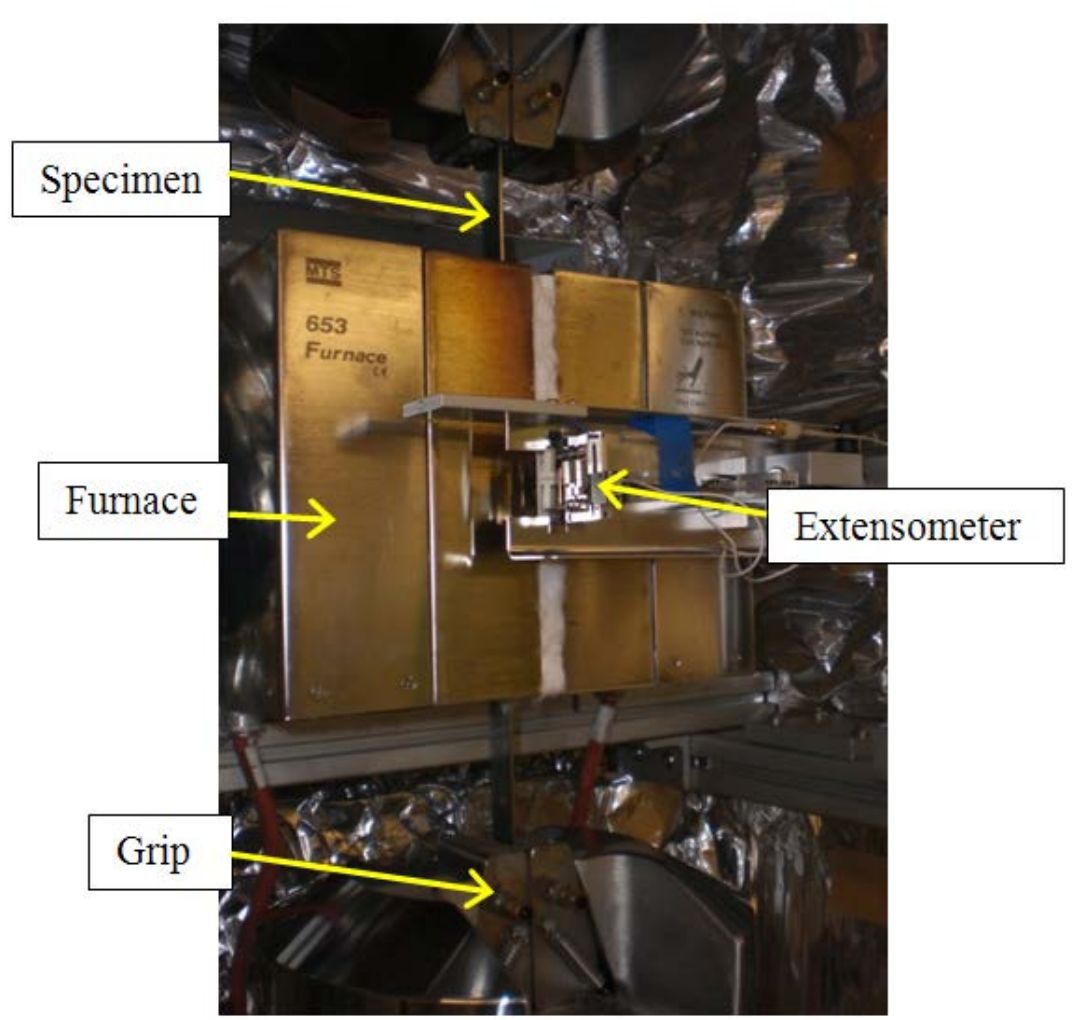

(b) Test set-up during testing

Fig 3. Typical test set-up 


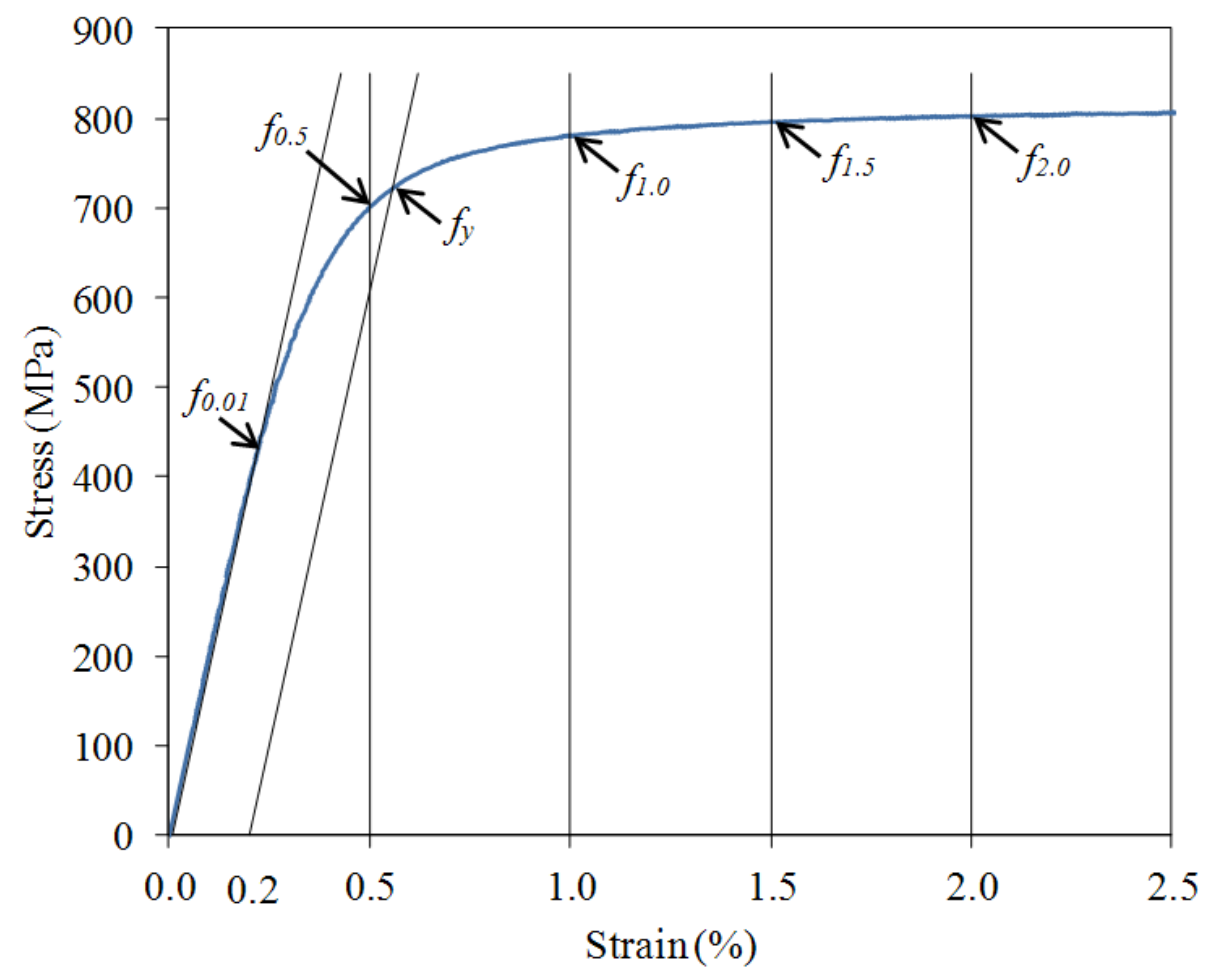

Fig. 4: Definition of symbols 


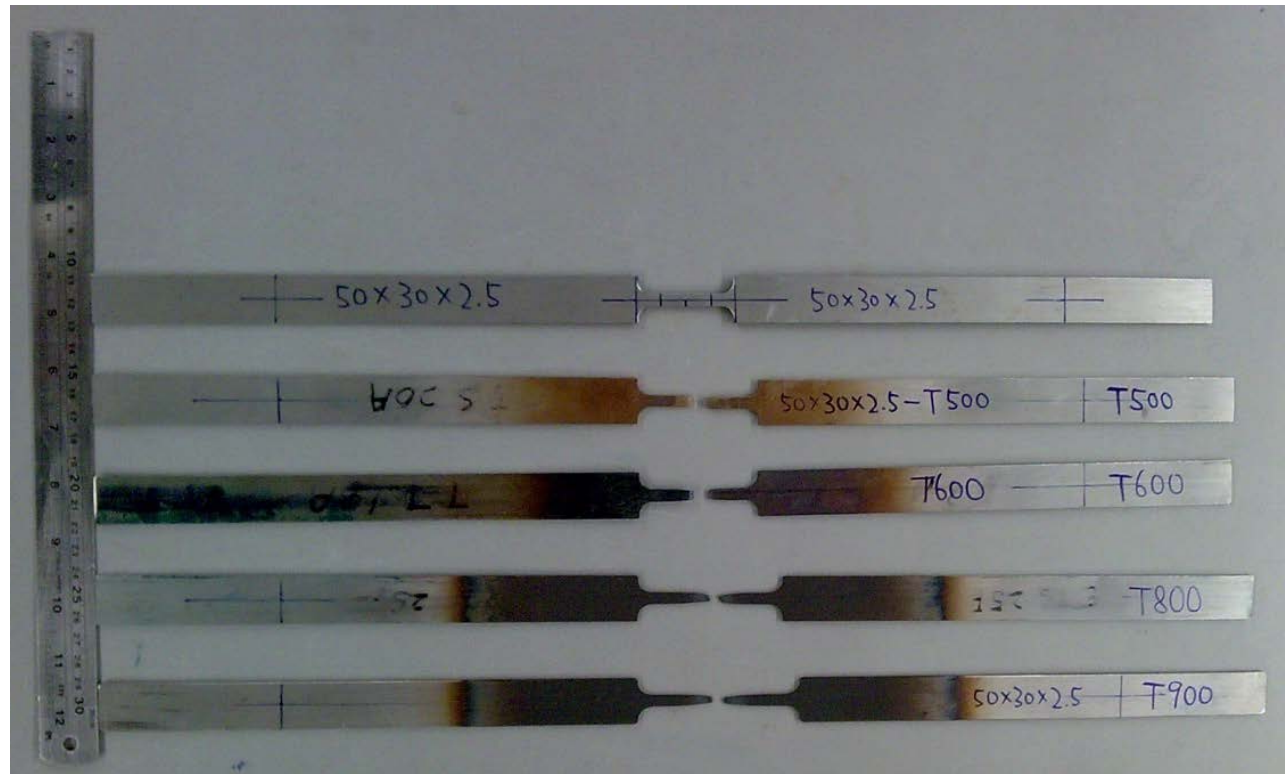

Fig. 5. Coupon specimens before and after tests at failure for different temperatures 


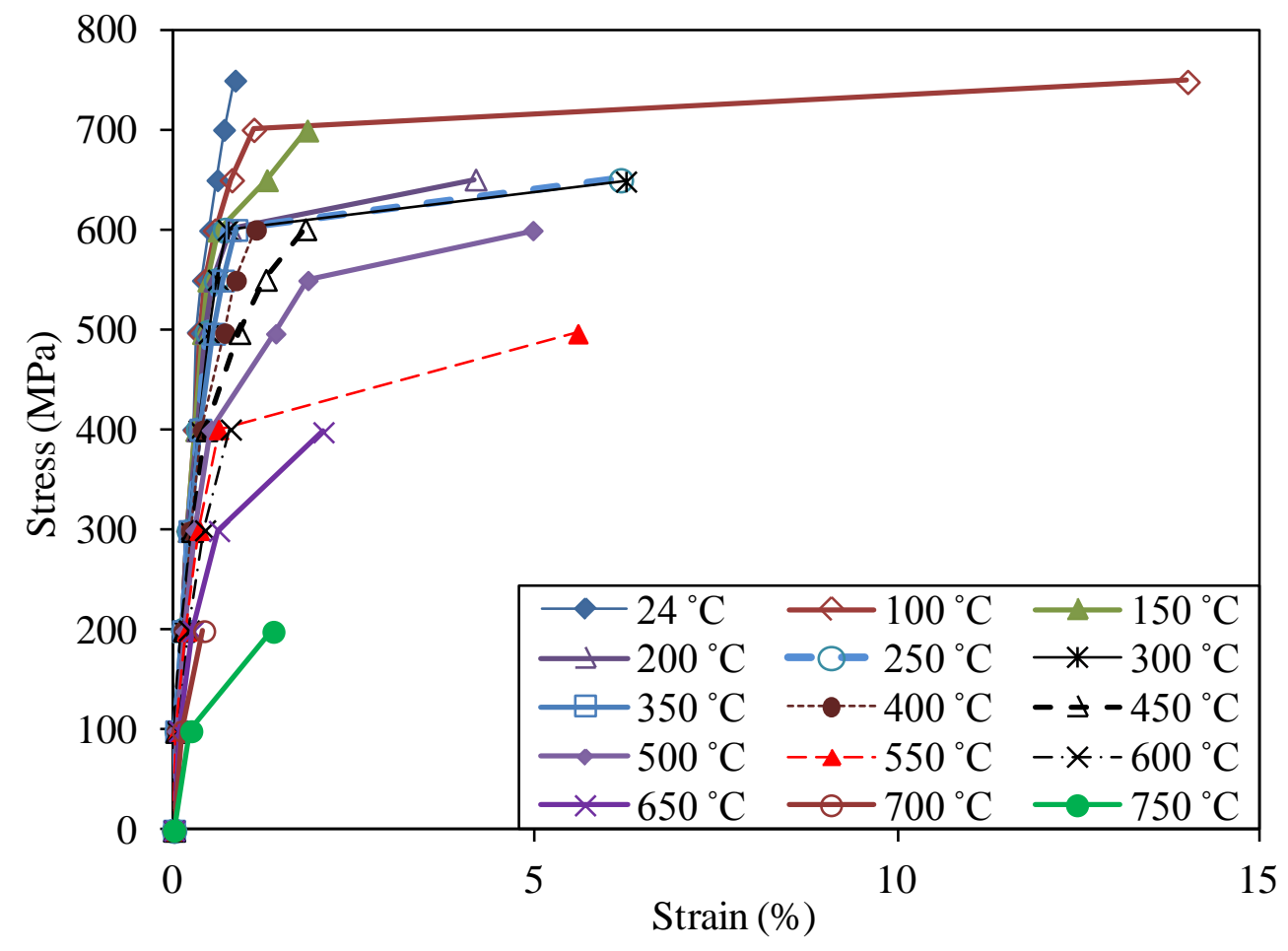

Fig. 6: Stress-strain curves of section $50 \times 30 \times 2.5$ at different temperatures obtained from coupon tests in transient state 


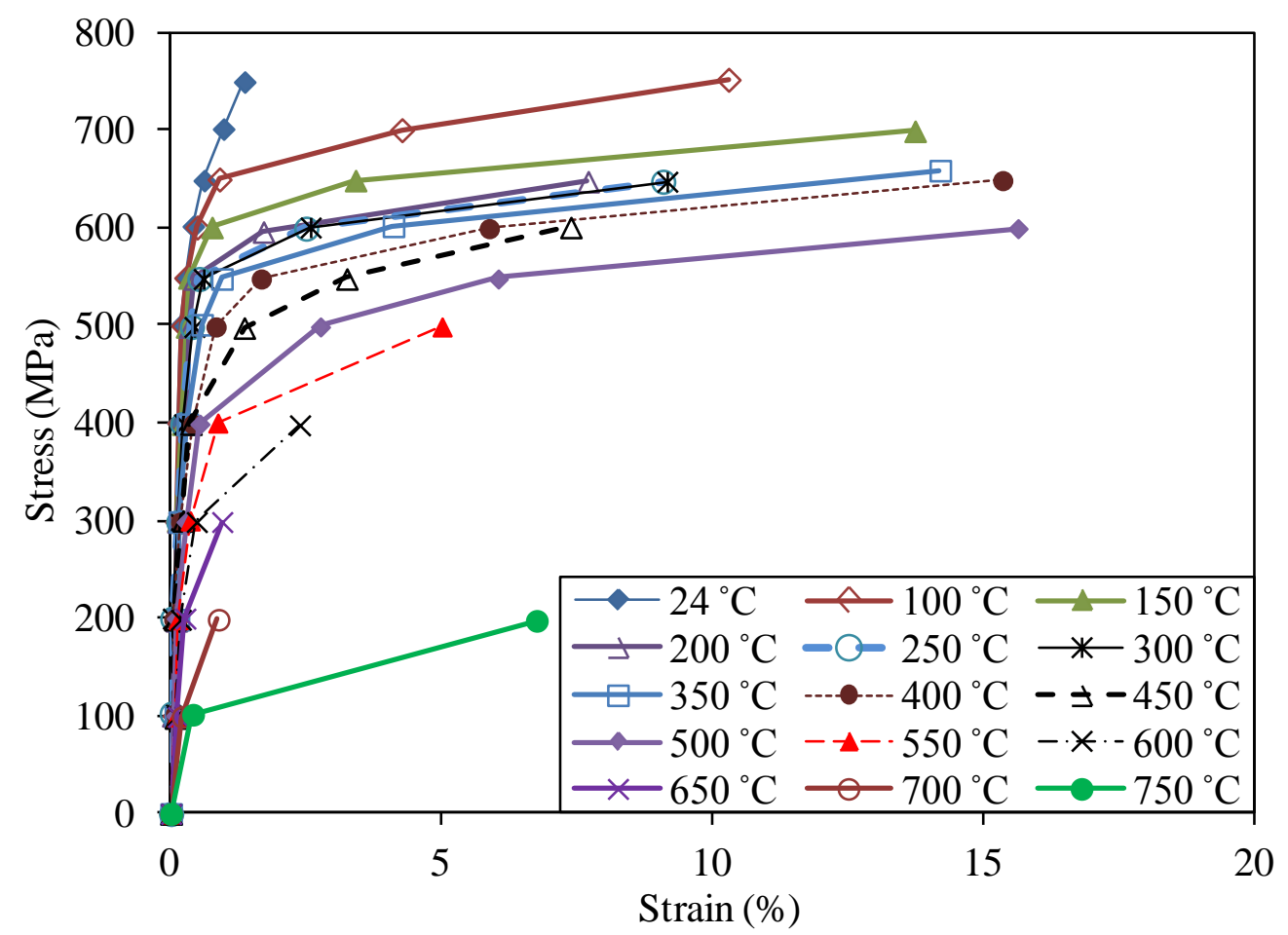

Fig. 7: Stress-strain curves of section $50 \times 50 \times 1.5$ at different temperatures obtained from coupon tests in transient state 


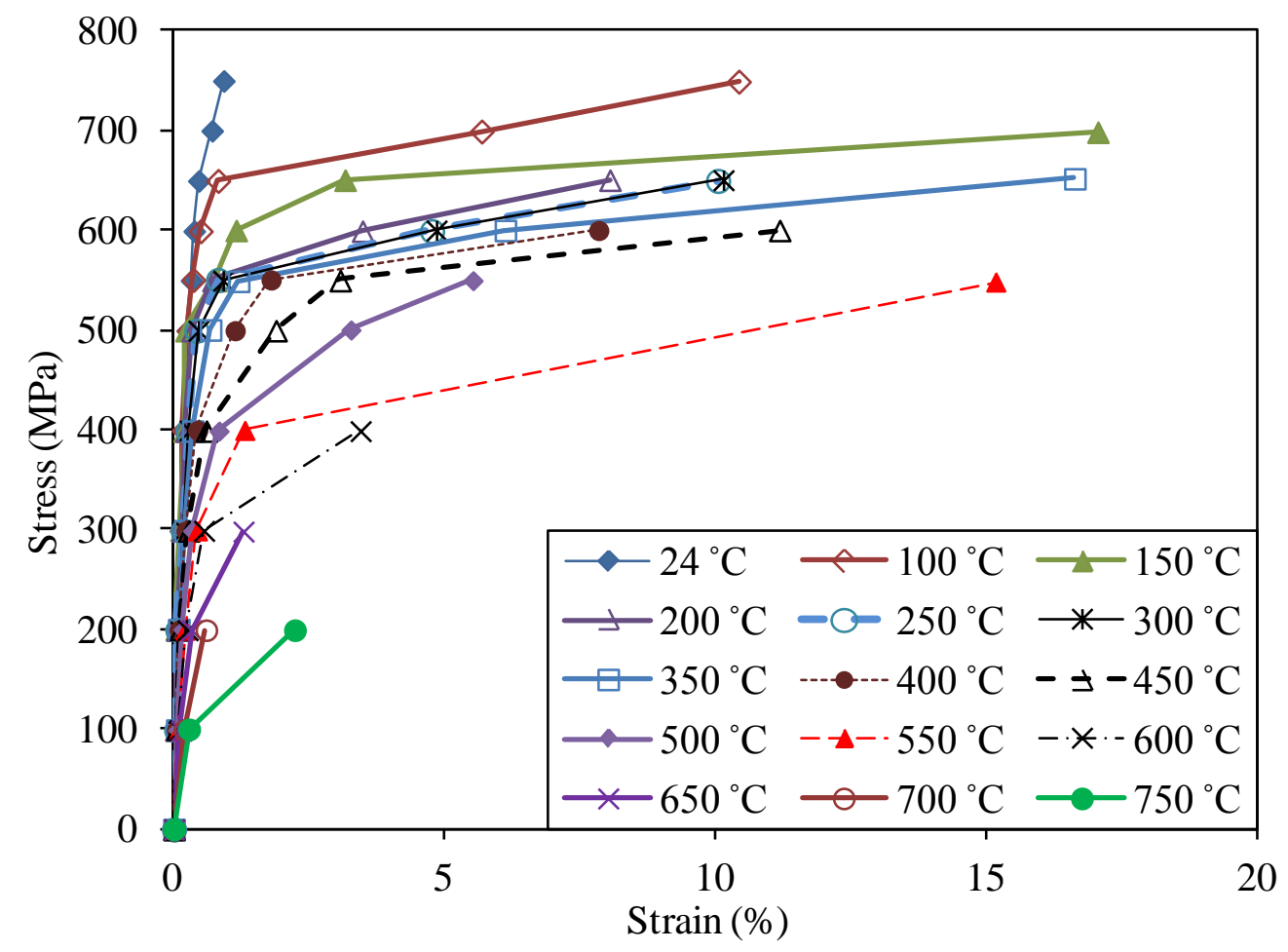

Fig. 8: Stress-strain curves of section $150 \times 50 \times 2.5$ at different temperatures obtained from coupon tests in transient state 


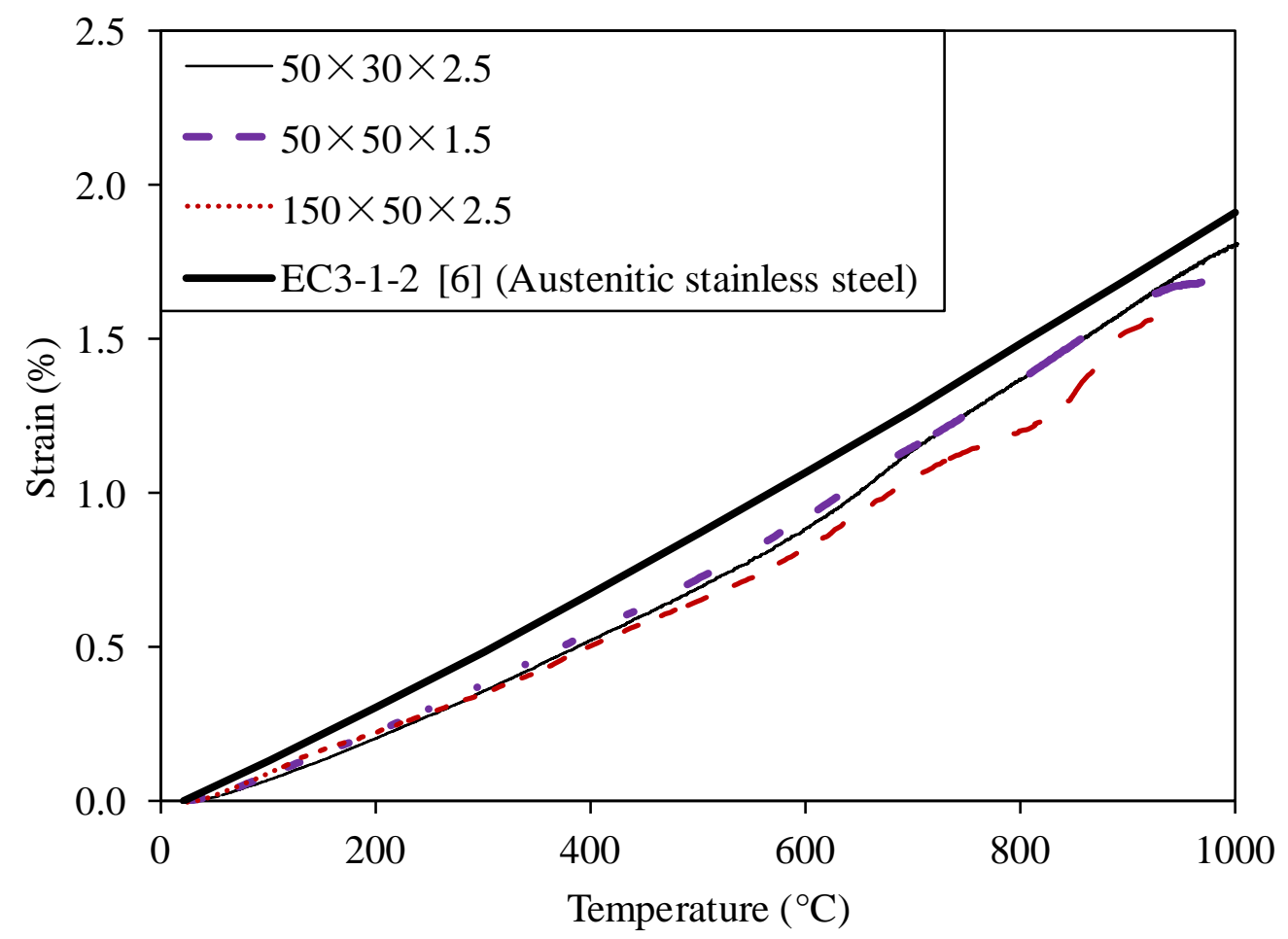

Fig 9: Comparison of thermal elongation predicted by EC3-1-2 with test results 


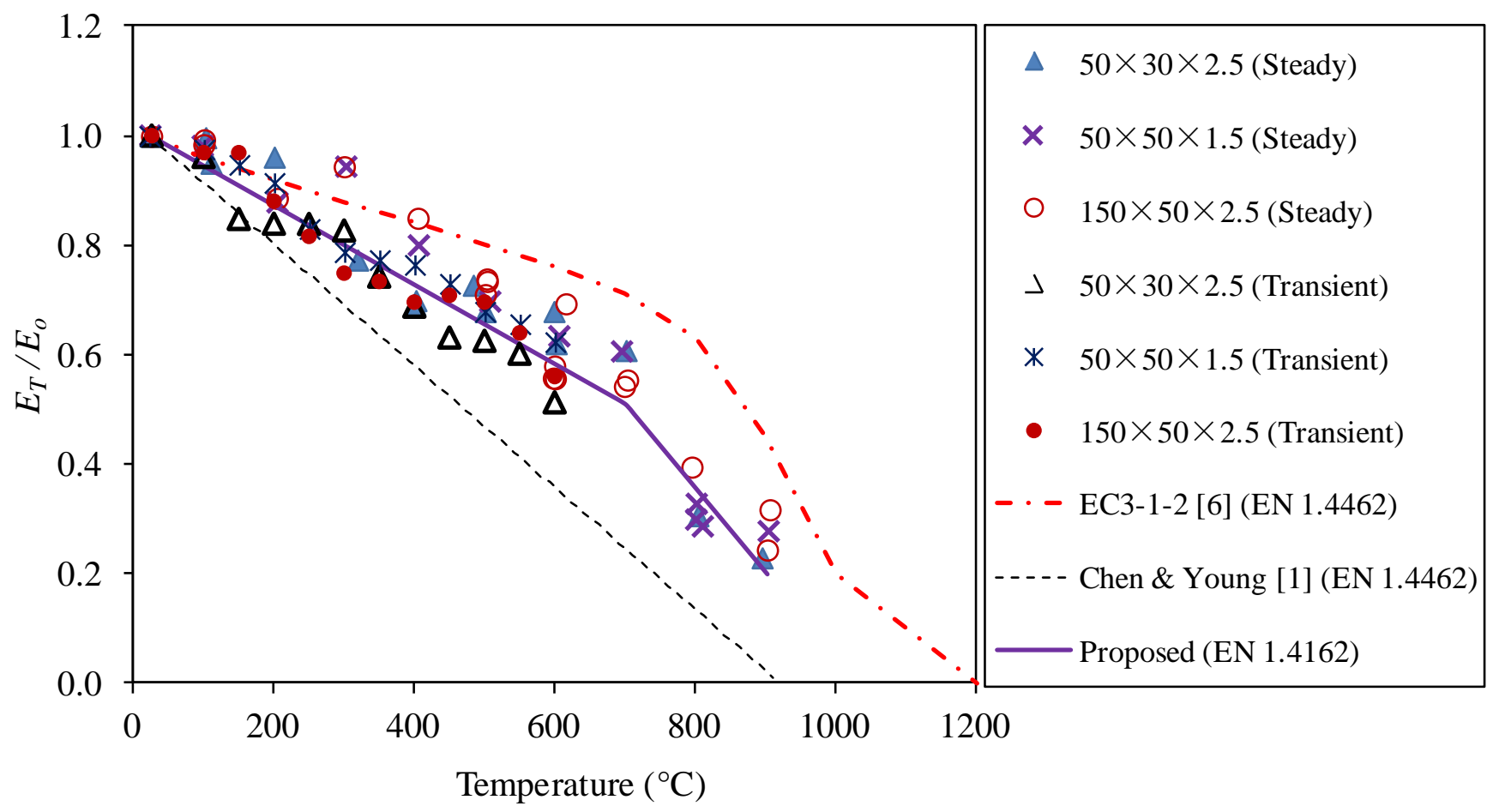

Fig 10: Comparison of Young's modulus obtained from design rules and test results 


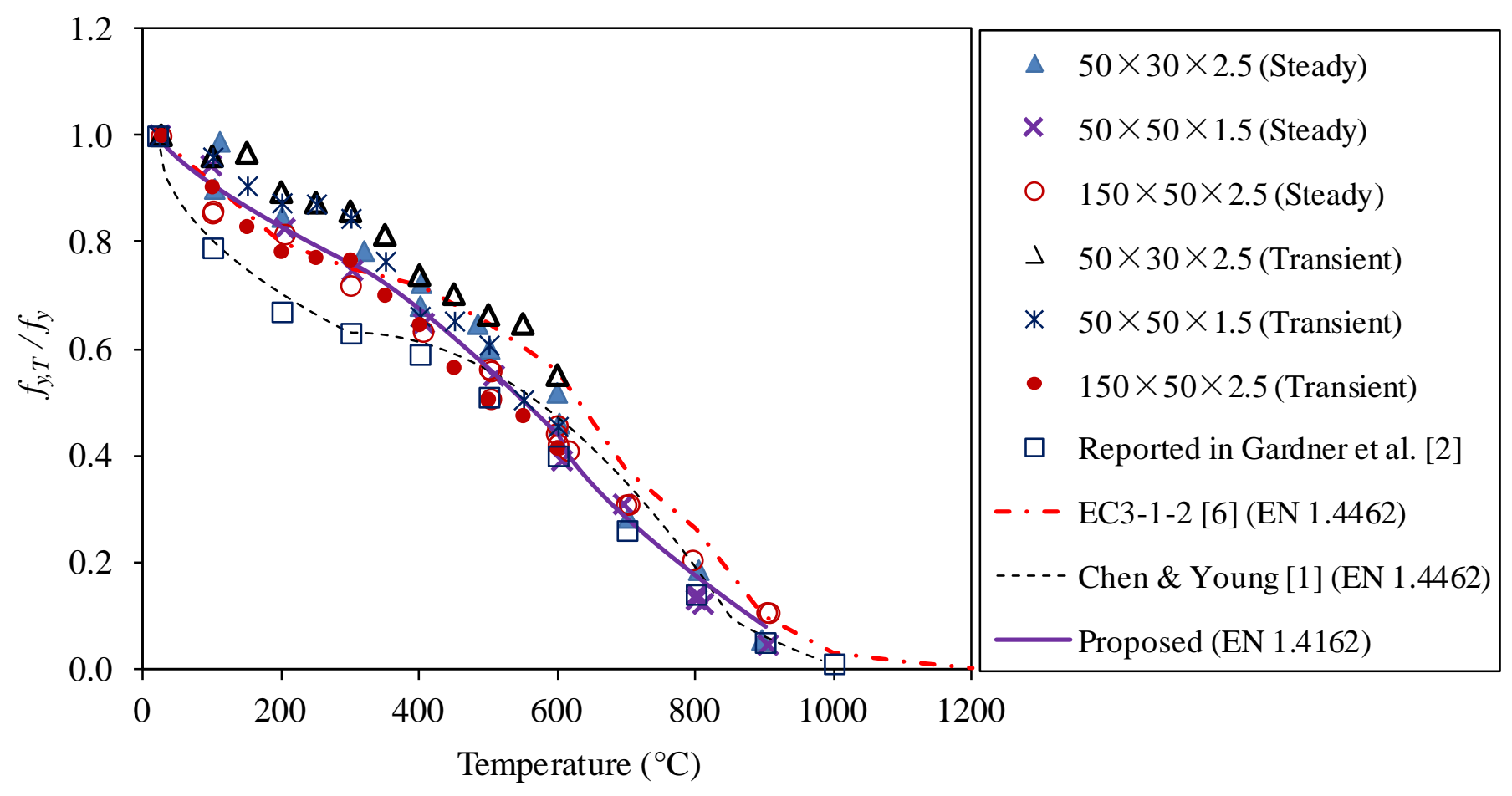

Fig 11: Comparison of yield strength obtained from design rules and test results 


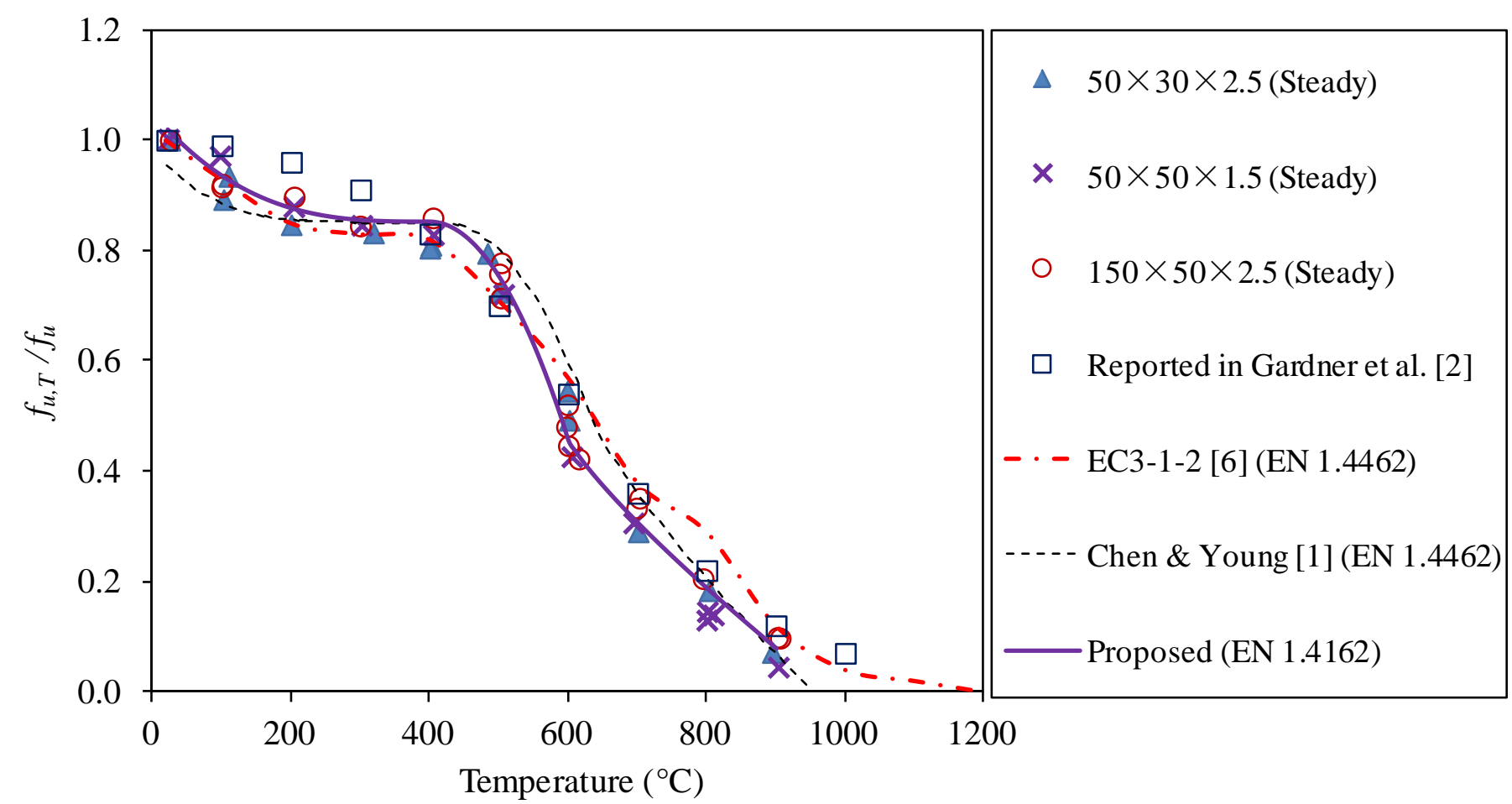

Fig 12: Comparison of ultimate strength obtained from design rules and test results 


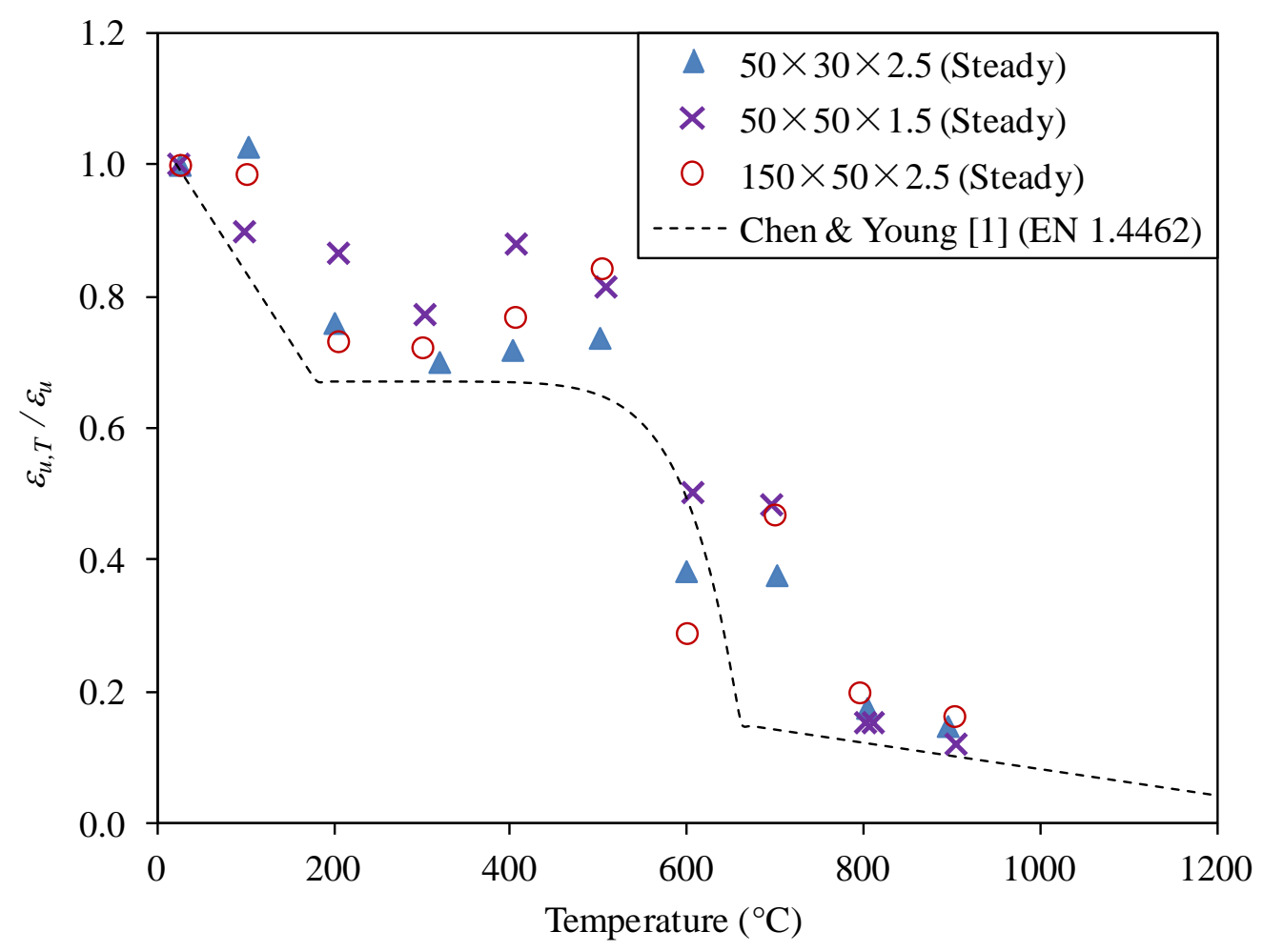

Fig 13: Comparison of ultimate strain obtained from design rule and test results 


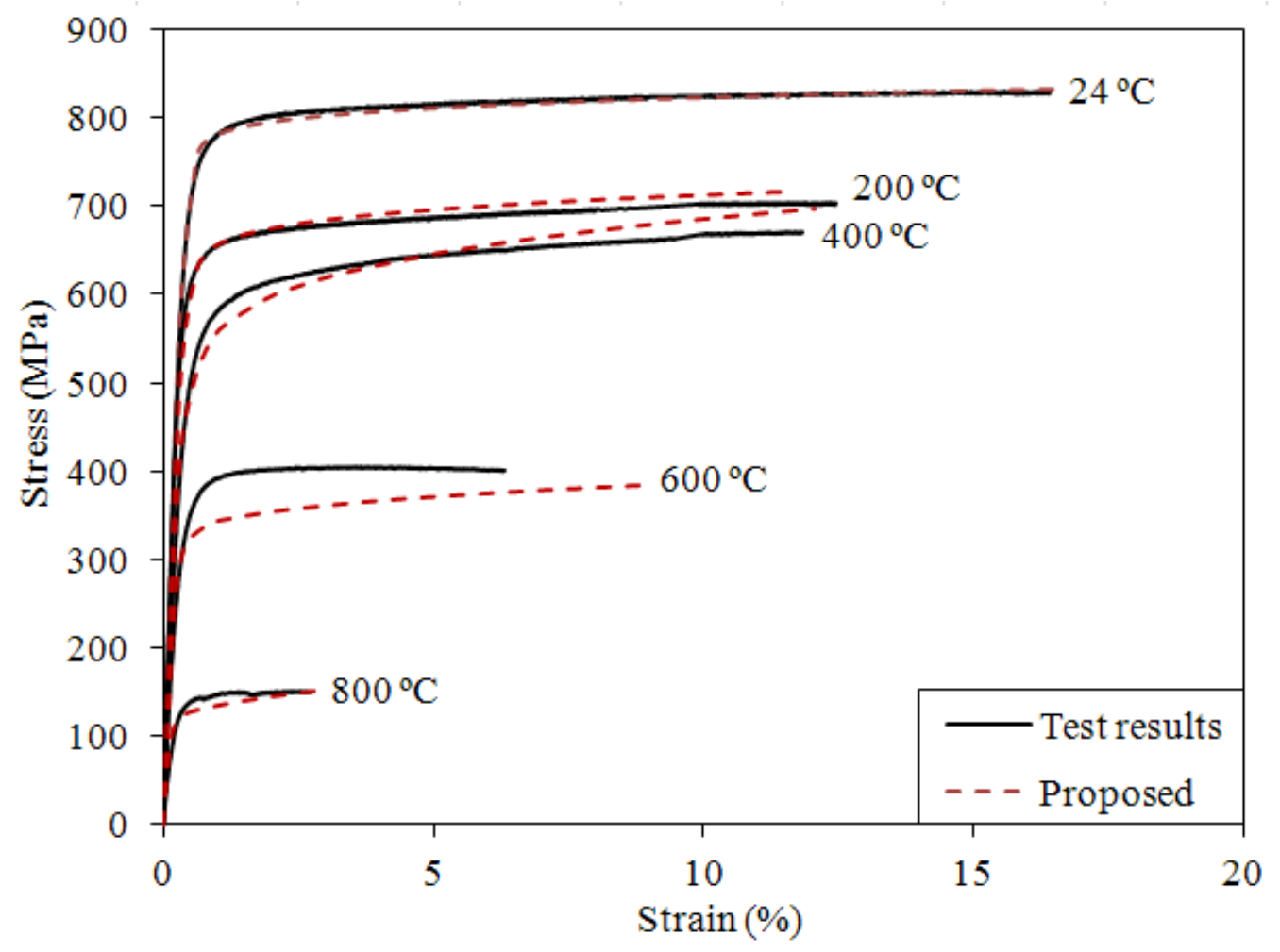

Fig. 14: Comparison of stress-strain curves predicted using the proposed coefficients in stress-strain model with test results for Section $50 \times 30 \times 2.5$ 


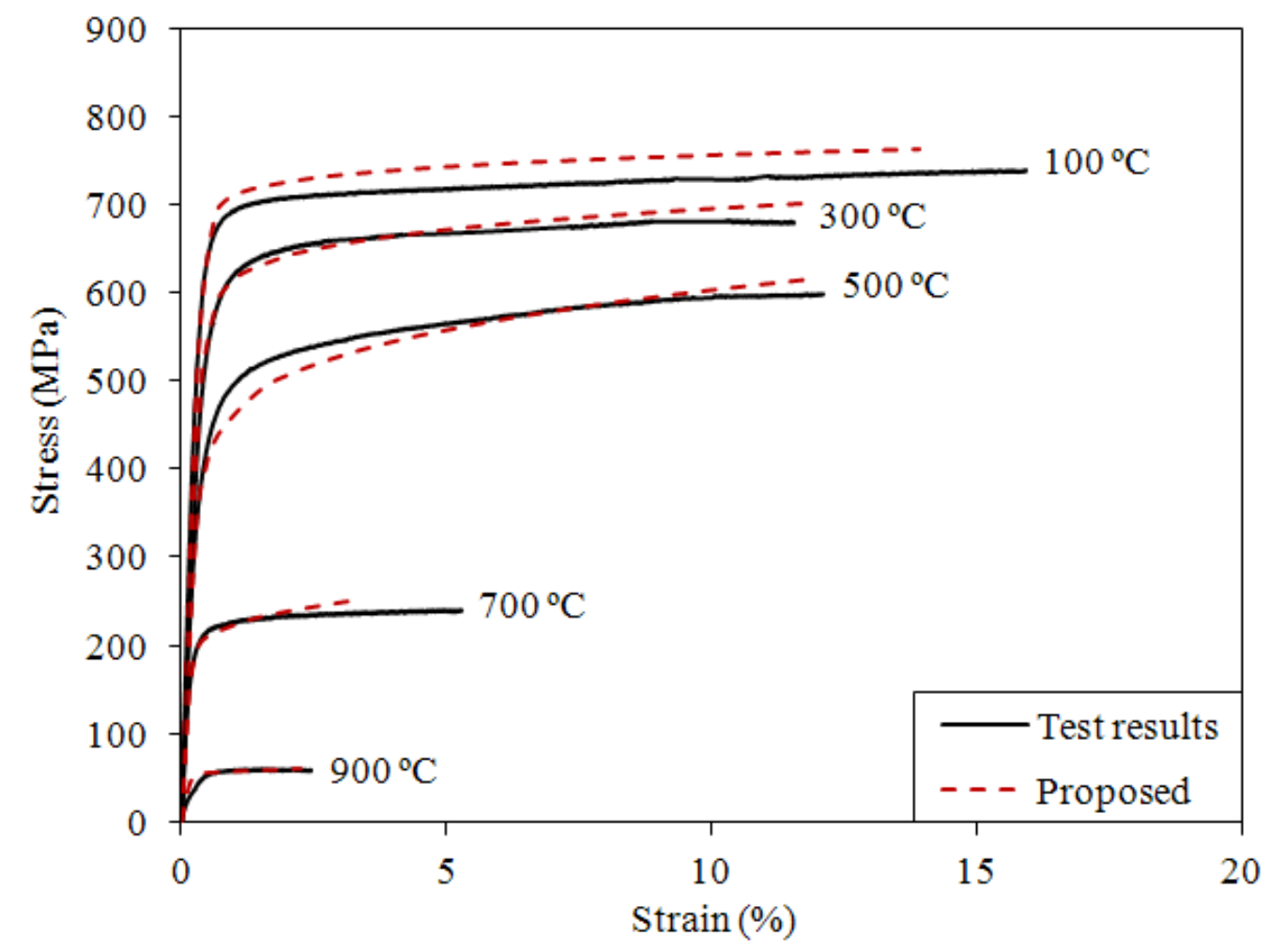

Fig. 15: Comparison of stress-strain curves predicted using the proposed coefficients in stress-strain model with test results for Section $50 \times 30 \times 2.5$ 


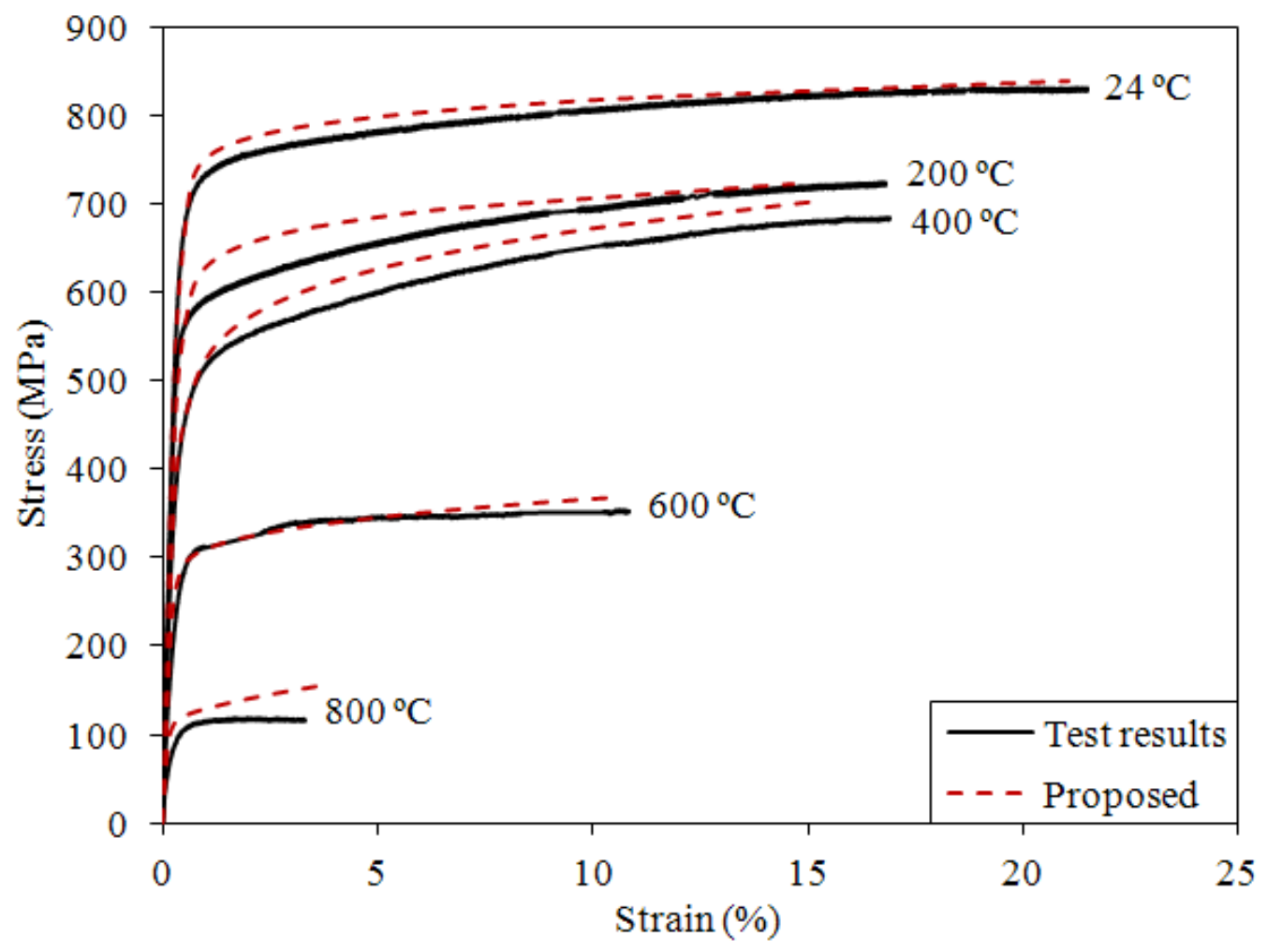

Fig. 16: Comparison of stress-strain curves predicted using the proposed coefficients in stress-strain model with test results for Section $50 \times 50 \times 1.5$ 


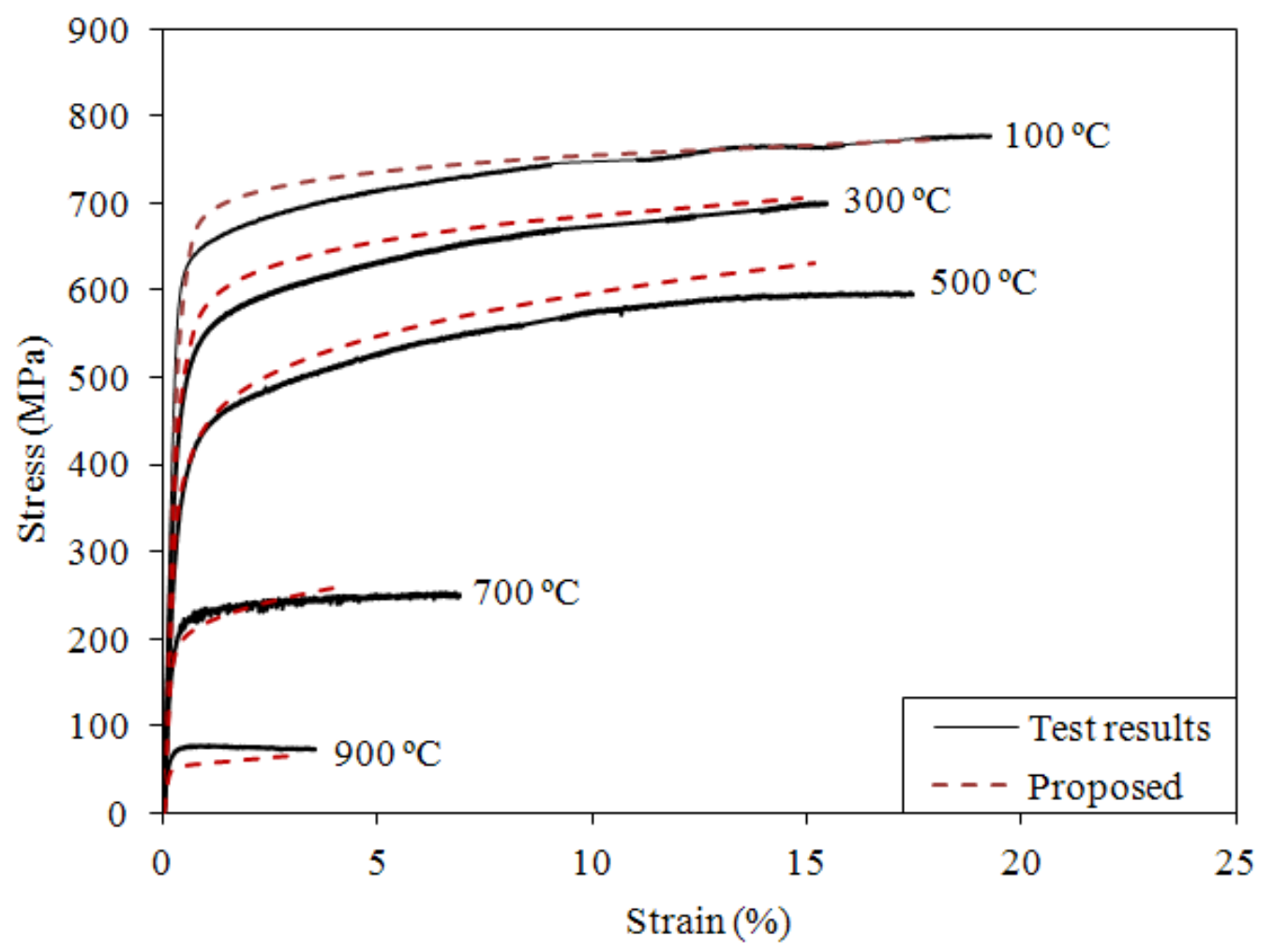

Fig. 17: Comparison of stress-strain curves predicted using the proposed coefficients in stress-strain model with test results for Section $50 \times 50 \times 1.5$ 


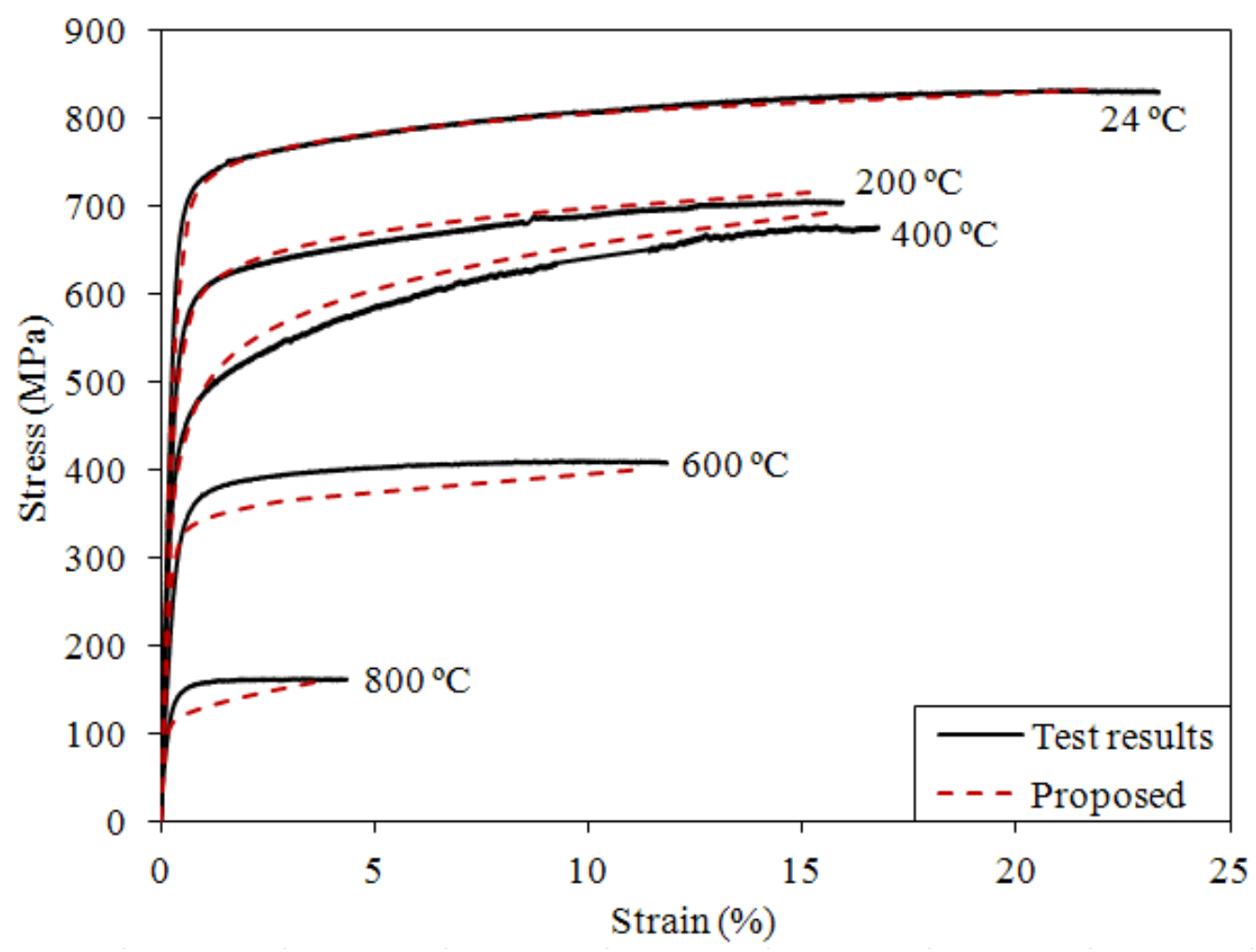

Fig. 18: Comparison of stress-strain curves predicted using the proposed coefficients in stress-strain model with test results for Section $150 \times 50 \times 2.5$ 


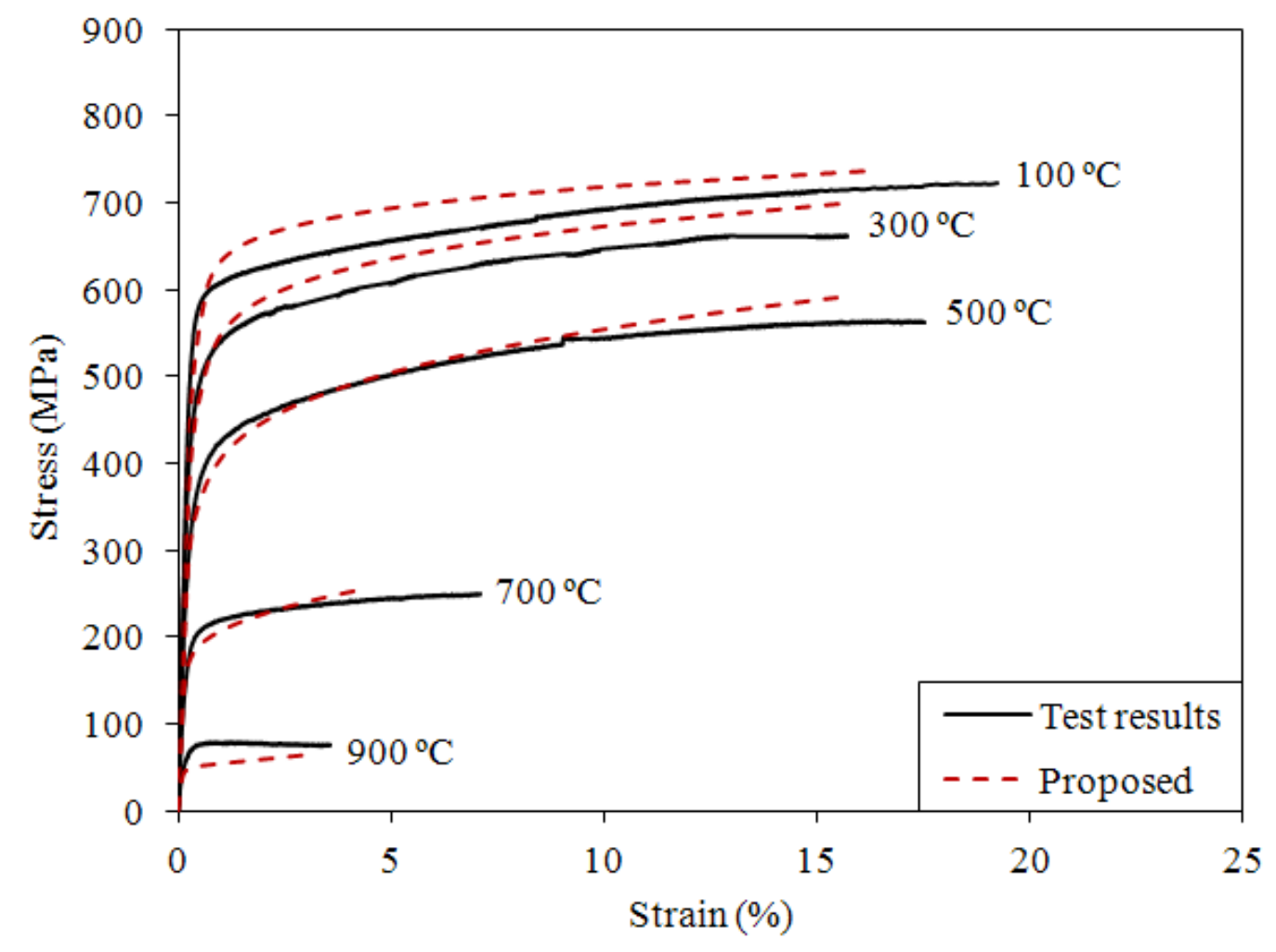

Fig. 19: Comparison of stress-strain curves predicted using the proposed coefficients in stress-strain model with test results for Section $150 \times 50 \times 2.5$ 